\title{
LA CREENCIA EN LA CIUDAD DE LOS CÉSARES DESDE CHILOÉ EN TIEMPOS DEL JESUITA NICOLÁS MASCARDI, 1666-1673
}

MARÍA XIMENA URBINA C. ${ }^{a}$

\section{RESUMEN}

El objetivo de este artículo es dar nueva luz sobre la creencia en la ciudad de los Césares, interpretándola no como una leyenda colonial, como ha hecho la historiografía hasta ahora, sino como una realidad que era totalmente factible en el imaginario de sus contemporáneos. Tomamos el caso del jesuita Mascardi, quien buscó a los Césares saliendo desde el colegio de Castro, provincia de Chiloé, en 1670. Considerando la documentación generada por él y por las autoridades contemporáneas, y añadiendo dos cartas hasta ahora no contempladas, nos alejamos de la clásica interpretación de Mascardi como un crédulo ingenuo para mirarlo en el contexto de la orden jesuita, de las autoridades y vecinos de Chiloé, y del virrey del Perú: todos creían inminente el hallazgo de la ciudad oculta de la Patagonia.

PALABRAS CLAVE: ciudad de los Césares, Nicolás Mascardi, estrecho de Magallanes, jesuitas, historia cultural, Chiloé, Chile.

\section{THE BELIEF IN THE CITY OF THE CESARES FROM CHILOÉ AT THE TIME OF THE JESUIT NICOLÁS MASCARDI, 1666-1673}

\begin{abstract}
The objective of this article is to shed new light on the belief in the city of the Césares, interpreting it not as a colonial legend, what historiography has done until now, but as a totally feasible reality for its contemporaries. We take the case of the Jesuit Mascardi, who looked for the Caesars leaving from Castro's school, province of Chiloé, in 1670. Considering the documentation generated by him and by the contemporary authorities, and including two letters not yet contemplated, we move away from the classic interpretation of Mascardi as having credulous wit to look at him in the context of the Jesuit order, the authorities and neighbours of Chiloe, and the viceroy of Peru: who believed the discovery of lost city in Patagonia to be imminent.
\end{abstract}

KEY WORDS: city of the Césares, Nicolás Mascardi, Strait of Magellan, jesuits, cultural history, Chiloé, Chile.

a Instituto de Historia, Pontificia Universidad Católica de Valparaíso. $\bigotimes$ maria.urbina@pucv.cl 


\section{INTRODUCCIÓN: MASCARDI EN LAS FUENTES E HISTORIOGRAFÍA}

El jesuita italiano Nicolás Mascardi, nacido en Sarzana en $1624^{1}$, misionero que sirvió en Chile, tiene fama de mártir por haber muerto a flechazos y boleadoras en manos de los indígenas a los que predicaba desde la misión en el lago Nahuelhuapi ( $41^{\circ}$ lat. S., en actual territorio argentino), de la que fue promotor y fundador (Nicoletti, 2014). Con ello se cumplió su deseo de predicar " $y$ exiliarme -diceen las partes extremas del mundo y vivir en ellas y entre miles de fatigas por mi Dios", como pide en su segunda carta indipetae ${ }^{2}$. Pero, sobre todo, su nombre ha trascendido por ser un "Parsifal" que buscaba un santo grial en la Patagonia: la ciudad de los Césares.

Llegado a Chile en 1652, fue enviado a la residencia de Buena Esperanza, en tierras de Arauco, donde tuvo de compañeros a los padres Diego de Rosales y Jerónimo de Montemayor, reencontrándose luego con éste último en Chiloé. Cuando en 1655 una rebelión indígena destruyó la misión, Mascardi pidió ser enviado a Chiloé, el confín austral americano, donde llegó al menos a comienzos de $1661^{3}$. Rosales, que por entonces estaba a la cabeza de la vice-provincia de Chile, elevó en 1662 la residencia de Castro a la categoría de colegio incoado y nombró a Mascardi como su primer rector. Éste, al poco tiempo pidió dispensarse del cargo para

1 Importantes semblanzas (además de la bibliografía que pronto citaremos) son: Terges (1946), que es un artículo de difusión que reseña el libro de Furlong (1945), Storni (1980, p. 178), Storni (1992), Broggio (2008), O’Neill y Domínguez (Eds).

2 Conocemos esta carta de 1643 y una anterior de 1640 gracias a Gaune y Rolle (2015). Esta carta está dirigida al Padre Muzio Vitelleschi, Prepósito General de la Compañía de Jesús. Los autores dan la siguiente referencia: Archivum Romanum Societatis lesu (en adelante ARSI), Fondo Gesuitico, Vol. 744, f. 132 .

3 Al menos desde el 7 de febrero de 1661 Mascardi estaba en Chiloé. Esa fecha tiene una carta enviada a Athanasius Kircher. Kircher, Misc. Epp. VIII, f. 70-71, Archivo de la Pontificia Università Gregoriana, 562, referida en Rosso (1950), p. 7.

4 Diego de Rosales, "Conquista espiritual del Reino de Chile". Se conserva todavía inédito en la Biblioteca Medina, de Biblioteca Nacional, Santiago de Chile, Tomo 307. Véase Hanisch (1985), sobre todo pp. 81-84.

5 "Vida apostólica y glorioso martirio del venerable P. Nicolás Mascardi de la Compañía de Jesús, Rector del Colegio de Castro, y misiones apostólicas de Chiloé, a quien envió el apóstol del Oriente S. Francisco Xavier a convertir a los gentiles poyas, guaitecas y otras naciones, y que muriese a atravesar los Andes y misionar a puelches y poyas, dos grupos de lenguas distintas entre sí, cazadores recolectores que habitaban las extensas pampas de la Patagonia que hasta entonces no habían recibido la visita de españoles -ni militares ni religiosos-, salvo las recaladas de los esporádicos barcos que cruzaban el estrecho de Magallanes. Además de su intención de ampliar la acción misional hacia nuevos y lejanos sujetos, también quería hallar una ciudad de españoles que, según noticias que circulaban, existía en el corazón de la Patagonia. Mascardi ardía de deseos por dar consuelo espiritual a aquellos descendientes de náufragos.

Diego de Rosales lo glorificó en algunos capítulos de su Conquista espiritual del Reino de $C_{\text {Chile }}^{4}$, y redactó dos "vidas" o relaciones sobre $e^{5}{ }^{5}$, valiosos escritos que contienen información de un conocedor directo de los hechos, pero, en contrapartida, con el objetivo de mostrar su vida como un camino al martirio final. Por eso, para aquilatar su papel en la creencia en la ciudad de los Césares, es indispensable relevar toda la documentación existente.

Algunas obras de los siglos XVIII y XIX retratan la actividad de Mascardi, pero sin incorporar nueva información documental ${ }^{6}$. No es el caso de Amunátegui, que publicó por primera y única vez los capítulos que sobre él había escrito Rosales en su Conquista espiritual ${ }^{7}$. En 1882 se

sus manos por nuestra Santa Fe". ARSI, Fondo Gesuitico, Vol. 851. Diego de Rosales, "Relación de lo singular del martirio del santo padre Nicolás Mascardi y de lo admirable de sus virtudes y milagros al N.R.P. General Paulo de Oliva", ARSI, Chile 5, fjs. 178-179v.

6 Por ejemplo, la Historia de la Compañia de Jesús en Chile escrita en 1736 por el P. Miguel de Olivares. Trata poco a Mascardi porque él mismo dice que le dedicará en forma especial una Vida o monografía, lo que finalmente no hizo.

7 Amunátegui, M. (1881), Tomo III, cap. 3, apartado "Incursiones del padre Nicolás Mascardi por la Patagonia", pp. 76-104. Analiza los viajes de Mascardi para argumentar cómo su presencia y recorridos desde Chiloé a la misión de Nahuelhuapi y desde ésta al estrecho de Magallanes fueron actos que muestran la autoridad del reino de Chile en esos territorios, en el contexto de los estudios sobre la delimitación de la frontera entre Chile y Argentina. Copia tres capítulos de La conquista espiritual (pp. 76-85, 9299 y 100-104), que toma de los papeles que José Ignacio Víctor Eyzaguirre había legado a la Biblioteca Nacional, hoy Archivo Nacional, Santiago (en adelante AN), Fondo José Ignacio Víctor Eyzaguirre, Vol. 27, pieza 14, fjs. 161$175 \mathrm{v}$. 
difundió el contenido de algunas cartas enviadas por Mascardi a su padre, en las que describía su vida en Chiloé (Neri, 1882, 1886) ${ }^{8}$. Pocos años más tarde Enrich aportó referencias de documentos que hasta entonces no se conocían (Enrich, 1891).

El jesuita Guillermo Furlong, ocupando por primera vez los documentos del archivo de la Compañía en Roma, dedicó varios libros, en gran parte apologéticos, a la actividad de sus correligionarios en el territorio argentino actual, tres de ellos a Mascardi (Furlong, 1943, 1945; Furlong et al. 1963). Desde Roma, Rosso, impulsado por haberse dado a conocer la Vida apostólica de Mascardi (Revelli, 1926), refirió la documentación existente, relevando su valor histórico y geográfico, porque "ilustra regiones en las cuales Mascardi fue el primer europeo en poner pie" (Rosso, 1950). Por último, en 1994 Téllez Lúgaro publicó una carta de Mascardi (Téllez, 1994).

Parte de estas fuentes han sido ocupadas en estudios dedicados a la misión en Nahuelhuapi (que a la muerte de Mascardi retomaron los jesuitas, hasta 1717, aunque con interrupciones) (García, 19431946, Porcel, 1958, Hanisch, 1982, Biedma, 1987, Nicoletti, 2004, Moreno, 2008, Urbina, 2008), al sitio mismo del establecimiento (Vignati, 1936, Hajduk, A. et al. 2013, y para subrayar la actividad geográfica de la orden (Barcelos, 2007, Barcelos, 2013, Page, 2013). Sin embargo, la relación entre el jesuita y la ciudad de los Césares no ha sido abordada por la historiografía, sino solo mencionada en los recuentos generales acerca de la "leyenda de los Césares"como se le ha llamado, como si fuese una ilusión ingenua de Mascardi, conjunta su objetivo de evangelizar a los poyas en Patagonia.

Planteamos que el buscar a los Césares fue un acto científico: sus expediciones son expresión de la misma "curiosidad infinita" de su maestro (Acuña, Ed., 2012), el políglota, sabio, erudito y reconocido científico, P. Athanasius Kircher, de quien recibió una sólida formación en Roma (Prieto, 2011, parte II, "Collaborative Enterprise". Asúa, 2014, cap. 4). Ella le llevó a aprender nuevas lenguas, a navegar y

8 Dice Neri que son cartas autógrafas conservadas por el abogado Carlo Bernucci, de Sarzana. Al parecer hoy se encuentran en la Biblioteca de la Universidad de Génova. El autor no individualiza las cartas, sino que hace un relato continuo.

9 La bibliografía sobre la ciudad de los Césares es abundante, y caminar para observar y describir, descubriendo la realidad -cielo, tierras y mareas- y comunicarla a su profesor (Rosso 1950, Biehl, 2004, Acuña, 2012. Acuña, 2014, Deckmann, y Biehl, 2014). Esta curiosidad también se expresó en hallar, por fin, la "ciudad de los Césares", tal como lo anhelaban otros jesuitas contemporáneos.

\section{LOS CÉSARES DE ARGÜELLO A MEDIADOS DEL SIGLO XVII}

La creencia en la existencia de la ciudad de los Césares en el corazón de la Patagonia es manifiesta en la documentación 9 . Su origen y nombre proviene de la "jornada" del capitán Francisco César, de la expedición de Juan Caboto, que internándose por el río de la Plata en 1529 regresó diciendo haber llegado a una población de indígenas con abundante oro y plata. Más tarde, no habiendo sido hallado aquel lugar, se atribuyó a los rumores sobre náufragos en las costas australes las riquezas de la ciudad vista por César. Las noticias dadas por indígenas lejanos cuando ocasionalmente eran contactados y preguntados por lo que había hacia el sur, la alimentaron y dieron lugar a diferentes versiones no excluyentes entre sí.

El supuesto oro, la ilusión de ser el primero en hallar lo nunca antes visto, o atender espiritualmente a hijos de cristianos ya sin sacerdote, fueron incentivos para su búsqueda. La creencia se mantuvo en Chile hasta fines del siglo XVIII, situándola en distintos lugares, activada por nuevas noticias (Urbina, 2019). Desde la perspectiva de la historia cultural, la ciudad de los Césares es una representación, considerada como una cosa sabida desde mucho antes. Con ella se interpretó o significó el espacio ignoto, lejano, vetado e inalcanzable que era el extremo sur americano, pero a la vez poderosamente atractivo. Decimos creencia y no leyenda o mito, porque ambas son categorías atribuidas por la historiografía decimonónica, que desconocen el sentido que tuvo para sus contemporáneos.

no es solo desde la Historia sino también desde la Literatura y el Ensayo, por considerársele un mito y una utopía. El trabajo que más ha considerado a las fuentes de manera directa y que trata a "la leyenda" en todo su proceso es Estellé y Couyoumdjian (1968). 
En Chiloé, la ciudad de los Césares era la de Argüello. Esto, porque en 1567 dos españoles se presentaron en Concepción diciendo ser sobrevivientes de un naufragio ocurrido hacía más de veinte años en el estrecho de Magallanes, de unos barcos enviados por el obispo de Plasencia. Siguiendo a un capitán de apellido Argüello, más de cien personas, entre hombres y mujeres, se habían internado para buscar mejores condiciones de habitabilidad, poblándose a orillas de un gran lago. Habiendo huido de ella, indígenas les indicaron dónde encontrar más españoles, pero de camino a Concepción, antes de cruzar la cordillera, dicen haber visto un poblado de incas del Perú con finos objetos de plata ${ }^{10}$.

Aquello concordaba con las noticias sobre incas que huyeron hacia el sur portando riquezas, que para 1587 dieron lugar a formales averiguaciones desde Tucumán ${ }^{11}$. Pocos años después, además, llegó a Chile la noticia de dos ciudades fundadas en la orilla norte del Estrecho en 1584, empresa realizada desde la metrópoli, cuyos habitantes al no recibir nuevos auxilios caminaron hacia el norte, acomodándose -se pensaba- en el corazón de la tierra ${ }^{12}$.

La ciudad de los Césares está más estrechamente vinculada a la provincia insular de Chiloé en los siglos XVII y XVIII, que a otro territorio, por ser el lugar poblado de españoles más cercano a Magallanes. Comparece en ello, también, el aislamiento en que quedó luego de la recuperación violenta de las tierras al sur de

10 Pedro de Oviedo y Antonio de Cobo dijeron en Concepción que quedaron en la orilla del Estrecho a los 52 $13^{\prime}$ más de cien personas, incluyendo trece mujeres, con armas y bastimentos. Un capitán llamado Sebastián de Argüello fue el líder quien los guió hacia el noreste, donde se asentaron conviviendo con indígenas, hasta donde están al presente, a la orilla de un gran lago. Ellos huyeron de allí, por haber dado muerte a un español, y llegaron a los 41 grados "a la población de un inga del Perú y sus gentes que están poblados de esta parte de la cordillera de Chile", quienes los escoltaron en su camino, en el que vieron una población con muchos objetos finos de plata. Los dejaron "en lo alto de la cordillera" en manos de los puelches a la altura de Villarrica, desde donde fueron hasta Concepción. Siendo huéspedes del maestre de campo general, Juan Gutiérrez de Altamirano, hicieron la "Relación de Pedro de Oviedo, natural del condado de Nieva, y Antonio Cobos, carpintero de ribera, personas que venían en los dos navíos del obispo de Plasencia, y dicen lo siguiente...", sin fecha, 1567 en
Concepción por parte de mapuches y huilliches en 1600. Sus intentos de revertir la incomunicación, tratando de alcanzar Chile por tierra o las orillas del Mar del Norte, le llevaron a estar alerta a las noticias procedentes de tierras más lejanas. La insularidad y la lejanía no son razones en sí mismas para la "credulidad", sino que la existencia de poblados desconocidos era factible, y las noticias sobre ellos, coincidentes.

\section{PROPUESTA: \\ MASCARDI, CHILOÉ Y LOS CÉSARES}

La historiografía acerca de la "leyenda" de los Césares ha considerado a Mascardi como el más célebre de sus creyentes. Pedro de Angelis, el primero que hizo una historia de la búsqueda de los Césares (1836) dice que participó del engaño, trabajando con ahínco para generalizarlo (Angelis, 1836, Tomo I, IV y V). Vicuña Mackenna considera la "leyenda" una infantil creencia de tiempos de los españoles; Barros Arana dice que los resultados de sus primeros intentos deberían haberlo hecho desistir, "como a cualquier hombre de juicio cabal", y que sus viajes "tienen algo de prodigioso" (Barros Arana, 1999) [1884-1902], Tomo V, p. 150). Fonck en 1900 usó los conceptos "leyenda", "místico" y "ficción poética" para referirse a Mascardi y relacionó su búsqueda con la del santo grial (Fonck, 1900, pp. 44, 494 y 497). Parsifal de los Césares le llamó Ciro Bayo en 1913, cuando hace una novela de la gesta mascardiana (Bayo,

Medina (1889, Tomo III, Dcto. CVII, pp. 465-468). En ella se dice, también, que el propio Altamirano había tenido ocasión de enterarse de "las mismas noticias referidas" mucho antes, en 1554, a través de un indio puelche cuando fue "sobre la cordillera de la Villarrica a una escolta por sal".

11 En 1587 y 1589 el gobernador de Santiago del Estero, Juan Ramírez de Velasco hizo averiguaciones sobre la existencia de incas instalados mucho más al sur de Tucumán, ricos en oro, plata y esmeraldas. Se les llama Césares. Ramírez de Velazco (1938).

12 Esto se supo porque el pirata inglés Cavendish pasó por el Estrecho y capturó a uno de los sobrevivientes, quien logró escapar en Chile y pudo dar noticia de las colonias. "Declaración que de orden del virrey del Perú D. Francisco de Borja, principe de Esquilache, hizo ante escribano Tomé Hernández, de lo sucedido en las dos poblaciones fundadas en el estrecho de Magallanes por P. Sarmiento de Gamboa". Lleva por fecha el año 1620. Fue publicada en Sarmiento de Gamboa (1768). 
1913, p. 117). Y así en adelante, Mascardi parece el epítome de la superstición y de la ceguera, y como tal, un personaje curioso.

Este artículo considerará a la ciudad de los Césares según las categorías de la época, atendiendo también a que, para entonces, la Conquista no estaba acabada, ni aun empezada en tierras patagónicas. Pretendemos mostrar que Mascardi no creyó más en la existencia de los Césares que los jesuitas que le eran contemporáneos, ni más tampoco que los españoles de Chiloé y las autoridades de la monarquía. Otros, como él, los buscaron por esos mismos años. Hallarla era de interés no solo local, sino general, pues el territorio efectivamente ocupado por la monarquía española se ampliaría a zonas hasta entonces vetadas. Para ello pondremos a Mascardi en el contexto socio-cultural de Chiloé, corregiremos errores de interpretación de las fuentes y aportaremos dos cartas no consideradas hasta ahora ${ }^{13}$. Éstas permiten repensar su supuesta inocente credulidad, para proponer, en cambio, que la existencia de los Césares era indudable y el problema era cómo encontrarlos en medio de una inconmensurable tierra de indígenas que impedían el paso. Si pudo acercarse es porque hubo una ocasión propicia para hacerlo. Actuó como vehículo de un interés local e imperial; monárquico y jesuítico.

El caso de Mascardi es una manera de aproximarnos a una mejor comprensión del sentido de la creencia en la ciudad de los Césares. Más que una idea inmanente que estaba en el ambiente y que se reactivaba cada tanto, su vigencia se explica por noticias dadas por indígenas no de frontera, sino ajenos, que a causa de coyunturas a nivel local o a nivel imperial, fueron especialmente atendidas por las autoridades. Por otro lado, el papel de la influyente y prestigiosa orden jesuita, que dio por cierta la ciudad en documentos y en acciones de búsqueda, tampoco ha sido considerado al explicarla. Quizá con ello se podría contribuir a pensar en nuevas dimensiones tanto locales como

13 Carta del gobernador de Chiloé al gobernador de Chile, Chacao, 29 de octubre de 1674. Archivo General de Indias, Audiencia de Chile, 7. Carta de Francisco Gallardo al P. Rodríguez de León, Chacao, 20 de mayo de 1670. ARSI, Chile 5, f. 158-161. Agradezco al historiador Jaime Valenzuela Márquez, profesor de la Pontificia Universidad Católica de Chile, haberme dado generosamente las globales de la orden, que es a lo que invitó $\mathrm{R}$. Gaune (Gaune, 2017).

\section{LOS JESUITAS Y LOS CÉSARES}

El P. Alonso de Ovalle, en su Histórica Relación del Reino de Chile publicada en Roma en 1646, dio cuenta de los náufragos del obispo de Plasencia, creyendo que podrían haber tenido descendientes mestizos, que serían los que llaman Césares. Eran noticias -dice- que "han corrido siempre muy vivas". No es el primero que lo menciona en un libro: en 1629 se llama "costa de los Césares" a la que corre desde Chiloé hasta el Estrecho (Vázquez de Espinosa, (1948) [1629], p. 697). Ovalle sabía que desde Chiloé se había ido a "descubrir" los "numerosos pueblos" de tierra adentro, que tienen "mucha riqueza de oro". Lo sabe porque participaron jesuitas, siendo el último Jerónimo de Montemayor, quien junto al capitán Navarro, en 1640 "descubrieron unas naciones que se piensan son estos Césares, porque son gente muy blanca y rubia", lo que llevó a pensar a Ovalle que puedan ser no solo descendientes de los españoles, sino de holandeses (Ovalle, 2003 [1646], p. 123-124).

Hay relaciones que son importantes para enunciar: Mascardi conoció a Ovalle en Roma antes de viajar a Chile, y leyó su libro (Rosso, 1950, p. 38). En la misión de Buena Esperanza fue compañero de Rosales, quien el año de la muerte de Mascardi terminó de escribir la Historia General del Reino de Chile. En ella, como en la Histórica Relación, los Césares existen. Rosales no habla genéricamente de los Césares náufragos del obispo, como Ovalle, sino que se refiere a los Césares de Argüello (Rosales, 1877 [1674], p. 32), y dedica un capítulo a explicar cómo se han buscado desde Chiloé ${ }^{14}$. Concilia esta versión con la de los incas huidos ricos, y concluye: "Y así hiciera gran servicio a las dos majestades el gobernador de Chile que buscase camino para descubrirlos y enviarles la luz del santo evangelio a

imágenes que de esta carta tomó en Roma, y que formará parte de este libro: Valenzuela (en prensa). Conocí la carta porque la cita Hanisch (1982, p. 139).

14 Ibidem, cap. XVII, "De los Césares y de la primera ciudad que se pobló en Chile con ese nombre hacia el Estrecho por los españoles de un navío que en él se perdió, cuya población no se ha descubierto", pp. 97-106. 
ellos y a los indios del Perú que están sitiados juntos hacia el Estrecho en la laguna referida, en distancia de 48 grados hasta 50". Dado que por Chiloé "son inaccesibles los caminos" para llegar a ellos, recomienda que sea por el camino de "la Villarrica, y pasar por él a los puelches" (Rosales, 1877 [1674], p. 106). Él mismo lo había transitado, yendo desde la misión de Boroa "a los indios puelches y pehuenches"15. Mascardi siguió ese consejo: llegar a los Césares desde los puelches. La ocasión se le presentó para ir a ellos no por Villarrica, sino por Chiloé. Cuando pidió autorización a sus superiores, el vice-provincial era Rosales.

Por otro lado, el P. Juan López Ruiz, cuya Vida fue escrita en la Conquista Espiritual, buscó a los Césares navegando hacia el sur de Chiloé en la década de $1620^{16}$, como también lo hicieron Juan del $\mathrm{Pozo}^{17}$ y Jerónimo de Montemayor, en 1640 (Rosales, 1877 [1674], p. 105. Estos dos últimos estaban en Chiloé cuando llegó Mascardi. También desde Mendoza se esperaba ir a evangelizar a los puelches y acceder más allá: "entre ellos, a pocas jornadas dicen que están los Césares, descendientes de españoles"18.

Las misiones de frontera en América fueron lugares privilegiados para obtener información de la tierra adentro, a través de la utilización del saber indígena para conocer y transitar (Lasa y Luiz, 2011). Ella circuló dentro de la orden -en

15 AN, Fondo José Ignacio Víctor Eyzaguirre, Vol. 27, f. 165. En 1649 se hizo una maloca para castigar a los puelches por saberse estaban preparando un ataque junto a dos holandeses de los que en 1643 habían atacado Castro. Se trata de la liderada por el capitán Luis Ponce de León, que salió desde Chiloé con 16 españoles y mil indígenas auxiliares y entraron a tierra de puelches por el paso cordillerano que estaba a la altura de la ya inexistente ciudad de Villarrica, destruida en "la gran rebelión" de los primeros años de ese siglo. Combatieron y llevaron a Chiloé 30 cautivos. Esa fue la ocasión en que el jesuita Diego de Rosales consiguió del gobernador de Chile que se le permitiese restituirlos a sus tierras, allende los Andes, por parecerle que los puelches no habian dado motivo alguno para ser castigados. Fue con dos españoles. Carta del capitán Francisco de la Fuente de Villalobos, veedor general de la gente de guerra, Concepción, 20 de abril de 1651, AN, Fondo Morla Vicuña, Vol. 20, f. 30v.

16 "Vida del Padre Juan López Ruiz", en Rosales (1991, p. 223-233).

17 "Letras anuas de esta provincia de Chile de los años 1629 y 30", Firmada por Gaspar Sobrino, en Santiago de Chile, 2 de abril de 1631, ARSI, Chile, Vol. 6, fjs. 63v-64v. Esta carta anua fue publicada por Ovalle (2003, [1646], p. 555-556). forma de cartas anuas, correspondencia, libros y cartografía ${ }^{19}$ - y fuera de ella: promovieron el hallazgo de aquel reino cristiano escindido para reincorporarlo a la Iglesia. Universalistas, querían llegar a todas partes para hacer del mundo completo una cristiandad. Por eso, conectar a esa ciudad en medio de tierras de gentiles con las ya cristianas implicaba, además, conseguir la evangelización de indígenas del intermedio.

\section{EXPEDICIONES CONTEMPORÁNEAS AL OTRO LADO DE LA CORDILLERA NEVADA EN BUSCA DE LOS CÉSARES}

Hay noticia de al menos tres expediciones hacia las tierras trasandinas en busca de los Césares cuando Mascardi estaba en Chiloé. La primera fue siendo gobernador Cosme Cisternas Carrillo (1663-1665). Solo se conoce por dos menciones tardías ${ }^{20}$, pero esta expedición debe ser la referida por Rosales, quien dice que el jesuita Juan Velázquez Alemán, "gran piloto", enviado por Cisternas a descubrir "un camino por mar", penetró al interior de la tierra firme por un río caudaloso, dejó las embarcaciones y subió a pie "las cordilleras nevadas" y se encontró con una laguna en $48^{\circ}$ "que le pareció era la de los Césares". Regresó a Chiloé planeando volver con mejor preparación para navegarla ${ }^{21}$.

18 "Letras annuas de la vice provincia de Chile a nuestro muy reverendo padre general Gostino Nikel, escritas por el padre Juan de Albiz, vice provincial de la vice provincia de Chile desde el año de 1657 hasta el de 1659", ARSI, Chile, Vol. 6, fjs. 282-282v. Esa carta anua de 1659 de la vice-provincia de Chile, recoge lo escrito por el colegio de Mendoza, provincia de Cuyo.

19 Por ejemplo, aparecen señalados "Los Césares" en el Tabula Geographica Regni Chile, de Alonso de Ovalle, 1646, Bibliothèque Nationale de France, département Cartes et plans.

20 Olivares, en 1736, dice que Cisternas envió algunas piraguas "al descubrimiento de los Césares", de Olivares (1874, p. 389) y Carvallo Goyeneche (1796), que por su orden se llegó a una isla grande y con buen puerto, a los $47^{\circ}$ de latitud sur. Carvallo Goyeneche (1865, Tomo IX, p. 144). Dice que fue en 1656, pero Cisternas no era gobernador por entonces, sino que lo fue entre 1663 y 1665. Urbina (2013 [1998], p. 27).

21 Rosales, D. La Conquista Espiritual... op. cit., reproducida en parte en AN, Fondo José Ignacio Víctor Eyzaguirre, Vol. 27, fj. 165. 
Una segunda búsqueda es consecuencia de una maloca ejecutada "a los puelches" en 1666, ordenada por el gobernador de Chiloé Juan Verdugo de la Vega ${ }^{22}$. Entre los cautivos llevados a Chiloé, además de la mujer que fue guía de Mascardi y de la que ya hablaremos, hubo otro que dio origen a una expedición que la historiografía no ha considerado. Francisco Gallardo, gobernador de Chiloé, escuchó del "puelche" Juan Guenuiquio cómo "más para el estrecho de Magallanes hay otra población según noticias que tiene de los suyos, que hay otra gente poblada con cabellos muy rubios y ojos zarcos y que se abren corona", que vivían a cincuenta leguas de distancia de "los argüellos"23. Gallardo envió una expedición costera (¿en 1667?) a buscarlos al mando del capitán Diego de Vera, con 20 hombres "bien armados" y 30 indios amigos conduciendo los bastimentos necesarios, para que entraran "veinte leguas más arriba de la Guaiteca [islas Guaitecas] rompiendo la cordillera que se nos opone por delante y miramos desde Chiloé". Pero el caudal de los ríos frustró el avance ${ }^{24}$. Es todo lo que sabemos de esta entrada, pero es bastante: su objetivo fue buscar a otros Césares, extranjeros, lo que no era extraño, considerando la presencia de holandeses en 1643 en Chiloé. Ovalle ya había anunciado esa posibilidad. Extranjeros o césares de Argüello, con los puelches en Chiloé parecía que se estaba a punto de encontrarlos.

22 Concepto en lengua araucana adoptado por los españoles para referirse a entradas militares rápidas a tierras del enemigo, para hacer daño, capturar individuos y venderlos como esclavos, actividad común por entonces en la frontera mapuche y en la frontera "de arriba". Juan Verdugo de la Vega fue gobernador de Chiloé en 1666 y 1667. Creemos que la maloca fue a comienzos de 1666 (enero, febrero o marzo) porque Mascardi, en carta de 30 de enero de 1669 dice que fue "tres años ha".

23 "Que más para el estrecho de Magallanes hay otra población según noticias que tiene de los suyos que hay otra gente poblada con cabellos muy rubios y ojos zarcos y que se abren corona y que ha pocos años que se comunican con estos...", los que están en la isla, separadas ambas poblaciones por no más de 50 leguas. Carta de Francisco Gallardo al P. Rodríguez de León, Chacao, 20 de mayo de 1670. ARSI, Chile 5, f. 158-161.

24 Idem. Gallardo no da fechas, pero dice que "la jornada" se hizo con orden del gobernador del reino Francisco Meneses (1664-1667), por lo que debió realizarse en el verano de 1666-1667 o 1667-1668.

25 "Descripción de las costas del Perú y Chile hasta cabo de Hornos y parte de la costa que va para Buenos Aires.
Una tercera expedición es la que solo se conoce a través de un mapa sin fechar (Fig. 1 ), pero que es de mediados del siglo XVII, que muestra un viaje en búsqueda de la población del "obispo Argüello" realizado por un tal Martín García Velasco, quien habría llegado cerca de la laguna donde estaba poblado, y luego habría salido al Mar del Norte por un río cercano a la latitud $46^{25}$, proeza no conseguida ni antes ni después. Podemos aportar que un derrotero poco posterior también la consigna, llamándolo Martín Velázquez, y agregando información sobre Mascardi: "entró por este estero en busca de la descendencia de Argüello". El autor del mapa está convencido de que será hallada en una "segunda laguna que presto se descubrirá" 26 .

Es en este ambiente (Fig. 2) que hay que situar el objetivo de Mascardi de llegar a tierras de poyas para utilizarlos como guías hacia la ciudad. Al comprobarse, otra vez por la expedición de Diego de Vera (¿1667?) que los ríos no servirían como vía para traspasar la Cordillera, la alternativa de ir "por los puelches" cobró fuerza.

\section{NICOLÁS MASCARDI Y FRANCISCO GALLARDO EN CHILOÉ}

De la maloca "a los puelches" de 1666 no hay más información, excepto lo que consta en

Contiene multitud de vistas y planos. 1764", fechado en Lima, enero de 1764, sin firma, en Archivo del Museo Naval de Madrid, Ms. 180 bis. Aunque el mapa es parte de un conjunto fechado en 1764, copia un mapa anterior, de mediados del siglo XVII. La "Descripción" fue dada a conocer por Martín-Merás (1986, p. 86). El mapa dice: "Desde la isla de Chilgue fue a cazar Martín García Velasco a las espaldas de Guiatica halló esta laguna muy mansa y muy buenos puertos que es Bitanquen se puede entrar 12 leguas más allá del Guafo camino Martín Velasco el río arriba en busca de la Ciudad de los Reyes y llegó hasta la + cerca de la laguna adonde dicen está poblado el Sr. obispo Arguëllo que se perdió en el cabo del Purgatorio y caminó con sus familias 60 leguas al NE y se juntó con los naturales y se pobló en una isla y laguna en 46 grados se entiende sin duda que está ahí faltole el bastimento y se volvió al desaguadero que sale a la otra mar tiene muchas corrientes".

26 "Derroteros de las costas del Pacífico desde California hasta el estrecho de Magallanes", Biblioteca Nacional de España, fechado erróneamente como c. 1699?, mapa $\mathrm{N}^{\circ}$ 48 http://bdh-rd.bne.es/viewer.vm?id=0000001261 


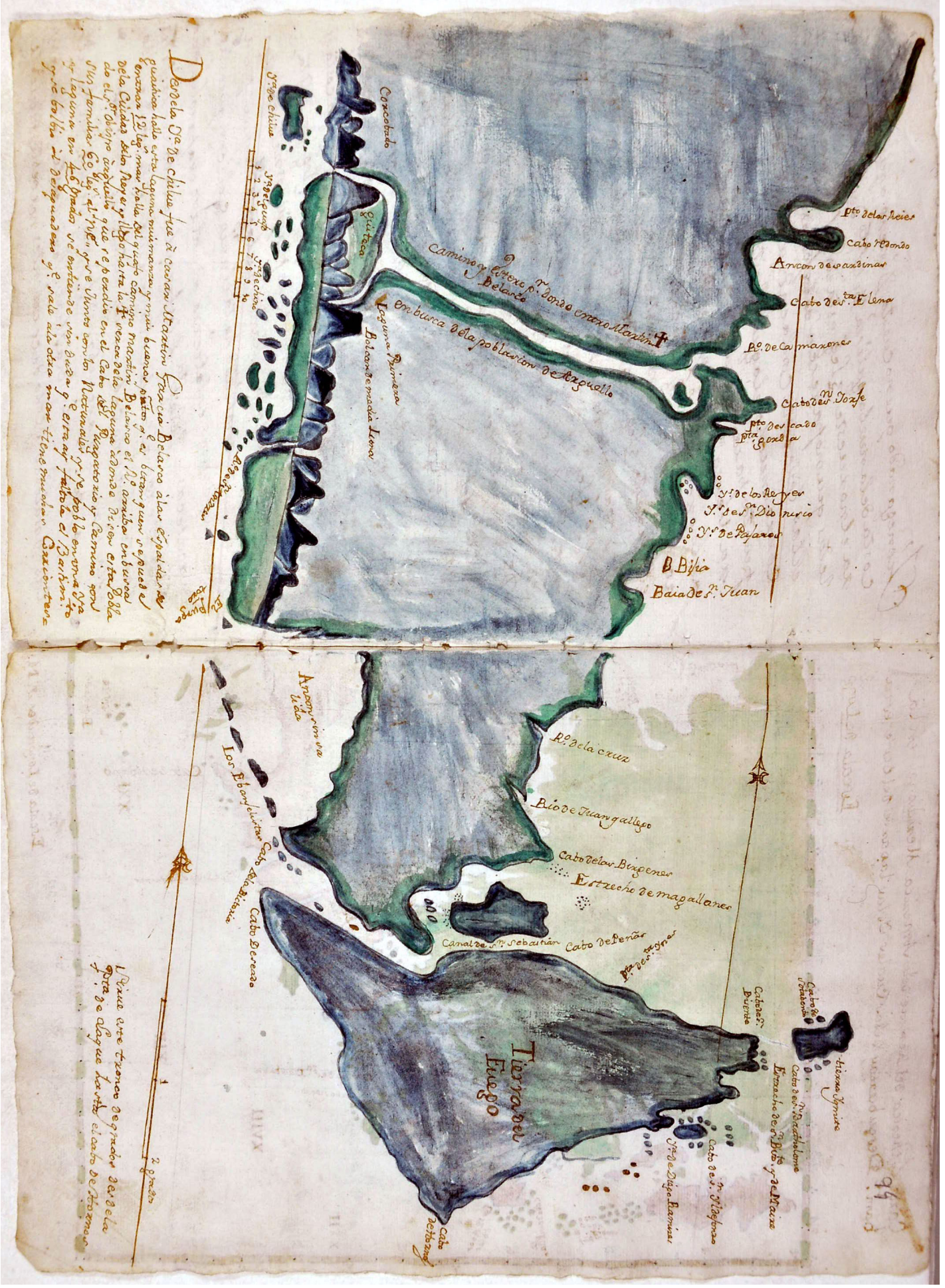

Fig. 1. "Descripción de las costas del Perú y Chile hasta cabo de Hornos y parte de la costa que va para Buenos Aires. Contiene multitud de vistas y planos. 1764", Lima, enero de 1764, sin firma. Archivo del Museo Naval de Madrid, Ms. 180 bis. 
a)

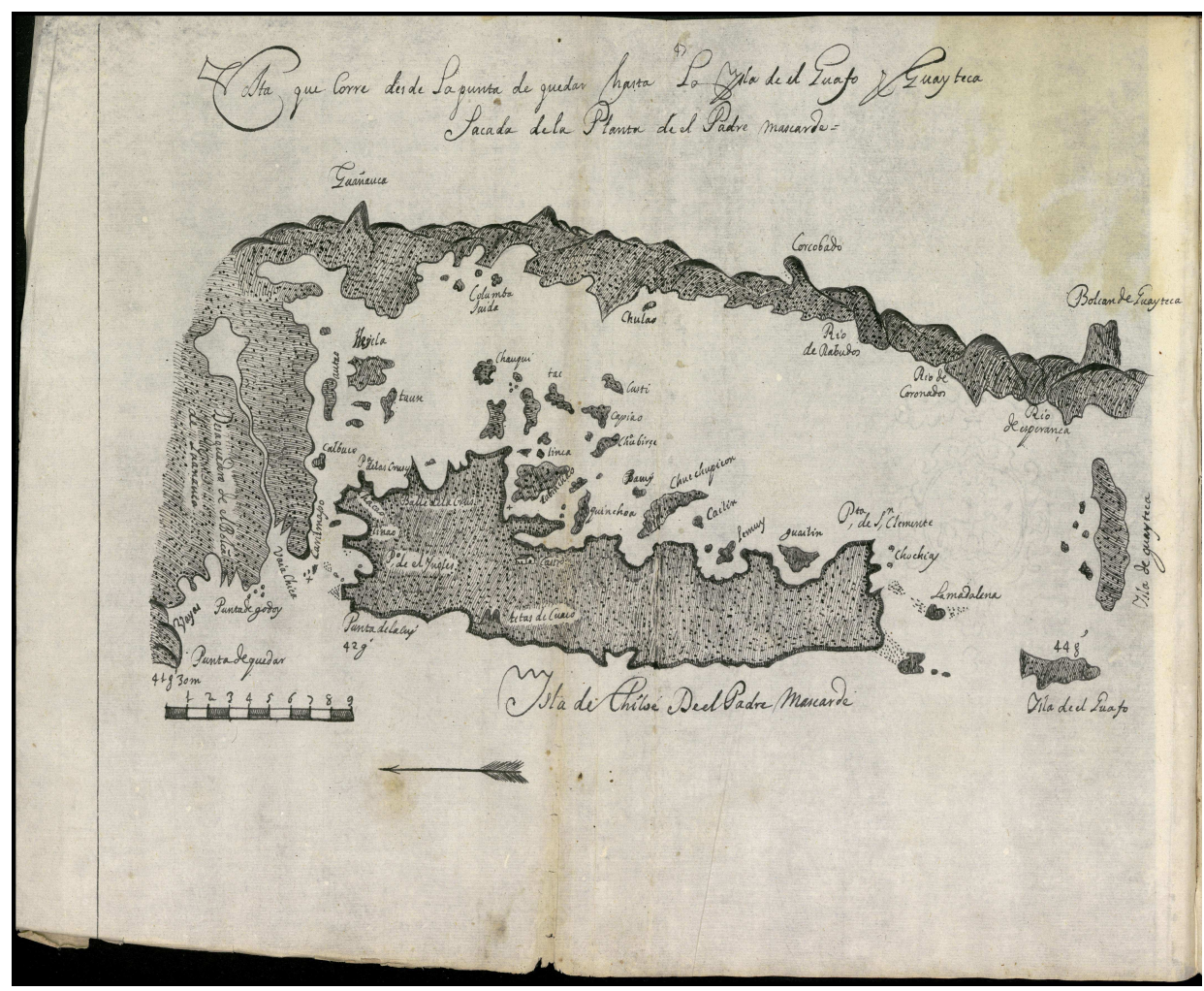

b)

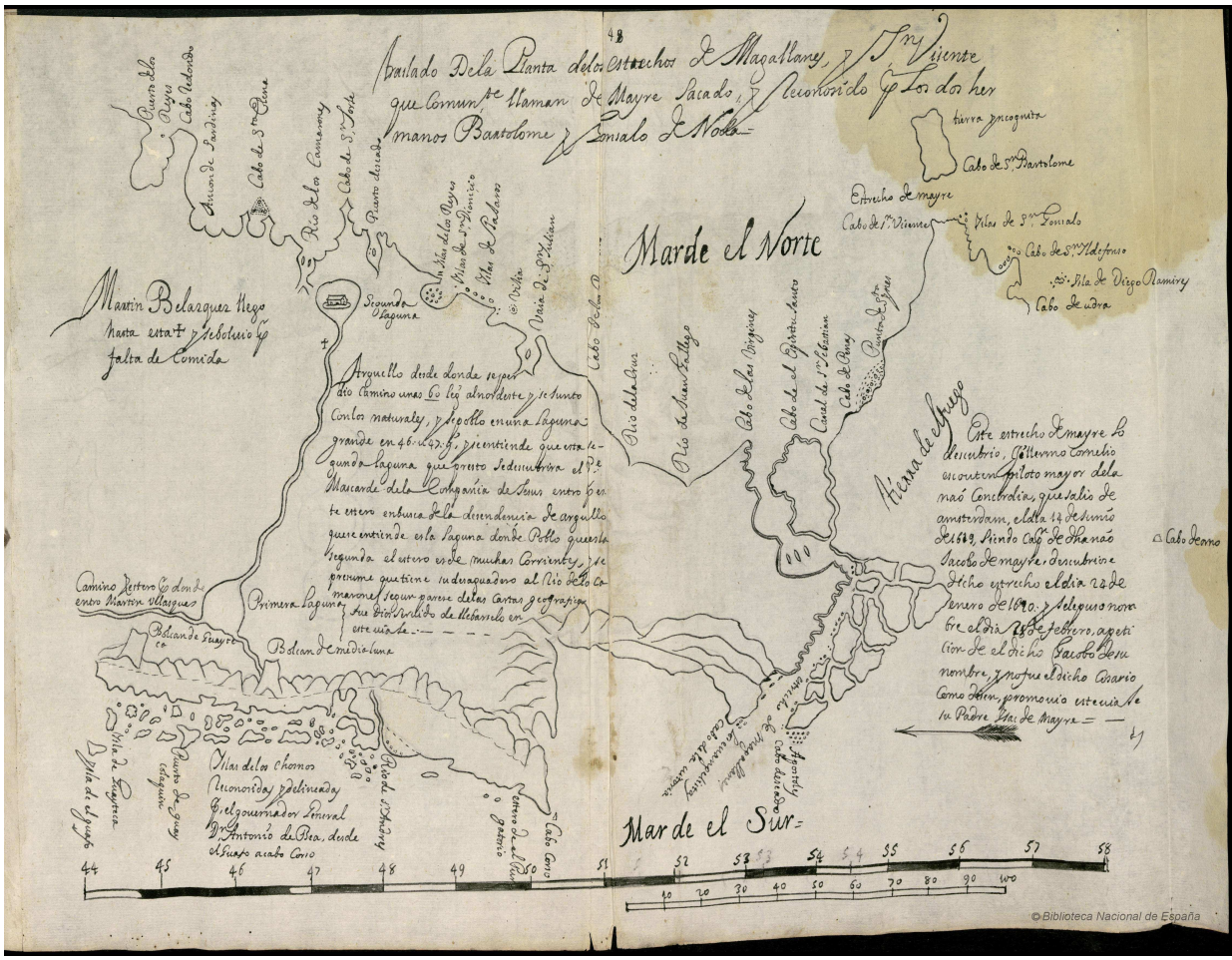

Fig. 2. a y b. Derroteros de las costas del Pacífico desde California hasta el estrecho de Magallanes, p. 71. Biblioteca Nacional de España. 
la documentación relativa a Mascardi. No se dice la ruta utilizada ni en qué paraje se ejecutó, sino solamente que el gobernador de Chiloé, Juan Verdugo de la Vega, nombró por cabo del grupo al capitán Diego Villarroel ${ }^{27}$. Volvieron con 31 cautivos $^{28}$.

Uno de ellos era una "india muy principal" a la que el resto reconocía como "reina". Por una carta no considerada hasta ahora, sabemos cómo todo se inició. Dice Francisco Gallardo, en ese momento corregidor de la ciudad de Castro, única de Chiloé (pero que antes había sido gobernador de la provincia, y después también lo volverá a ser): "me notició el capitán D. Francisco Cubillos de lo que apuntaba la dicha reina, si bien lo había hecho al general Alderete gobernando la provincia ${ }^{29}$, nada de esto le hizo armonía"30. A Gallardo, en cambio, "le hizo armonía", quizá porque a diferencia de Alderete, él era natural de Chiloé. Hizo llevar a la reina desde el fuerte de Chacao a Castro, la acomodó en su casa y consiguió una intérprete, porque su lengua era la poya y no era conocida en Chiloé ${ }^{31}$. Ella dijo que "sabía que muy lejos de su tierra habitaban españoles en una isla grande y rasa, que ésta estaba vecina a la Mar del Norte,

27 Rosales, D. Conquista Espiritual..., reproducida en parte en AN, Fondo José Ignacio Víctor Eyzaguirre, Vol. 27, f. 166.

28 Ese es el número que da el gobernador Gallardo en 1670. Carta de Francisco Gallardo al P. Rodríguez de León, Chacao, 20 de mayo de 1670. ARSI, Chile 5, f. 158-161. Aunque las fuentes hablan principalmente de puelches, Mascardi dice que en Nahuelhuapi también concurrían los poyas, que hablaban otra lengua. Rosales dice que la india era de nación poya, venida desde los confines del estrecho de Magallanes y que había ido a la zona a ver unos parientes. Rosales, D. Conquista Espiritual..., AN, Fondo José Ignacio Víctor Eyzaguirre, Vol. 27, f. 166. No pretendemos despejar aquí el panorama étnico comprometido entre los conducidos a Chiloé.

29 Quienes han estudiado el tema, R. Urbina y G. Guarda, dicen que a Juan Verdugo de la Vega, gobernador desde 1666, le sucedió Rodrigo Navarro. R. Urbina dice que ello fue en el mismo año 1666 y Guarda dice que en 1667 (Urbina, 2013, p. 28; Guarda, 2002, p. 44). Esta carta muestra, por lo tanto, que al menos temporalmente, Juan de Alderete, nacido en Chiloé y que dos veces antes había sido gobernador, lo fue de nuevo en 1667 o 1668, lo que hasta ahora no estaba registrado. Además, indica que la mujer no habló de inmediato, sino al menos un año más tarde.

30 Carta de Francisco Gallardo al P. Rodríguez de León, y que los dichos españoles comunicaban con los indios que están arrimados a esta cordillera [...], y que pasaban de ella en embarcaciones a labrar minas que tienen de oro, cuyos granos eran como pepitas de manzanas [...], que el lago que ceñía aquella isla le comunicaba un brazo de mar que entraba de la del Norte". Los pobladores tenían mariscos en abundancia y se aprovechaban del ganado vacuno y las caballadas existentes entre las pampas de Buenos Aires y el Estrecho ${ }^{32}$. La ciudad de españoles era rica y bien provista de todo, a diferencia de Chiloé. Mascardi hablaba de esto con la reina en su propia lengua, por haberla aprendido de tres de los cautivos, tal como antes de ir al archipiélago de los Chonos había aprendido la de los "caucau" conducidos a Chiloé. También, como en esa ocasión, formó a los tres como "fiscales" 33 .

Escribió en enero de 1669 a su superior en Lima que se había al fin presentado la ocasión de comunicarse con "la ciudad de Argüello". La reina, como autoridad de aquellos lugares, abriría el camino. Esto, aunque siempre lo habían impedido los indígenas, dice Mascardi, la reina, por agradecimiento al buen trato y bautismo, "ha descubierto lo que tanto deseábamos" 34 .

Chacao, 20 de mayo de 1670. ARSI, Chile 5, f. 158-161.

31 Gallardo hizo que se le llevase "una prima hermana suya", también capturada, que "sabía hablar la lengua de los indios de Chiloé”, es decir, el mapuche. Más tarde, Mascardi apuntó que los habitantes del norte del lago Nahuelhuapi (puelches) hablaban "la lengua general" (el mapuche). Es decir, la "prima" de la "reina" traducía del poya al mapuche. "Carta y relación que escribió el P. Nicolás Mascardi a los PP. Bartolomé Camargo, rector de Chiloé, y Juan del Pozo y Esteban de Carvajal, de lo que sucedió en la entrada que hizo a los indios puelches y poyas siendo el dicho P. rector de Chiloé", De los Poyas y octubre 15 de 1670, ARSI, Chile 5, f. 162-167v.

32 Carta de Francisco Gallardo al P. Rodríguez de León, Chacao, 20 de mayo de 1670. ARSI, Chile 5, f. 158-161.

33 Les enseñó, en la lengua que hablaban, las oraciones, catecismo y los misterios de la Fe. Antes de partir, dice, hizo un catecismo, confesionario y gramática en lengua puelche. "Capítulo copia de una carta escrita por el padre Nicolás Mascardi de la Compañía de Jesús, rector del colegio de Chiloé, al padre Joseph María Adamo de la misma Compañía, procurador general de la provincia de Chile que asiste en esta corte de Lima, en 30 de enero de 1669". El virrey conde de Lemos a la reina, Lima, 26 de mayo de 1669. Archivo General de Indias (en adelante AGI), Audiencia de Lima, Legajo 68.

34 Idem 
En preparación, escribió cartas en varios idiomas a la ciudad ${ }^{35}$, que llegarían gracias a los indígenas que -dice- darían paso, porque "por estar ésta con su gente en rehenes, se ven obligados a descubrirse". Dice: "Y si es cosa cierta y viene claridad de todo, a mi me tocaría la suerte de ir a consolar esos pobres puelches y españoles mientras su majestad o el virrey dispone otro mayor consuelo de tanta gente cristiana y descendiente de ellos. Yo pedí y tengo ya licencia del padre provincial de ir allá en viviendo cosa cierta..." ${ }^{36}$. Recibió lo que él interpretó como cosa cierta: un libro de horas o devocionario enviado por un cacique poya llamado Salatil, a través de Aquillo, "hermano" de la reina, que Mascardi reconoció como hecho en Sevilla hacía doscientos años, por lo que "es casi cierto que es de la gente del Argüello"37. También, por lo dicho por unos caciques enviados desde Chiloé "a los poyas", que vieron entre ellos objetos españoles, como ropa de paño, pretales de cascabeles, cuchillones, sombreros y otras cosas que no podrían, dice Mascardi, haberlas conseguido de españoles de Chiloé o de Chile ${ }^{38}$. Hubo, además, otras dos informaciones. El ya mencionado Juan Guenuiquio dijo haber visto cuarenta años atrás a dos españoles "que dijeron venir de aquella tierra adonde están poblados", pero se les impidió el paso $^{39}$. Además, Rapulga, el indio puelche enviado por Mascardi a Nahuelhuapi para anunciar su llegada, regresó diciendo que había "infinita gente y más capaces que ellos [los puelches] pues hablaban algunos vocablos castellanos por estar vecinos con los españoles perdidos" 40 .

Mascardi en enero de 1669 dice estar esperando la aprobación de su viaje por parte de sus superiores ${ }^{41}$. Obtenido, se nombró al P. José

35 Lo hizo en varias lenguas: "latina, española, italiana, griega, chilena, puelche y poya”. Rosales, D. Conquista Espiritual... AN, Fondo José Ignacio Víctor Eyzaguirre, Vol. 27, f. 168.

36 "Capítulo copia de una carta...". El virrey conde de Lemos a la reina, Lima, 26 de mayo de 1669. AGI, Audiencia de Lima, 68.

37 Idem.

38 Idem.

39 Carta de Francisco Gallardo al P. Rodríguez de León, Chacao, 20 de mayo de 1670. ARSI, Chile 5, f. 158-161, f. $160 v$.

40 Idem.

41 Hay una carta de Mascardi al vice-provincial de Chile que del Pozo como su reemplazante en la rectoría. Luego solicitó el permiso al gobernador de Chile y al virrey "por ser nuevo descubrimiento" 42 , documentos que no han llegado hasta nosotros. No pedía ni dinero ni escolta: iba solo, pero llevaba a los cautivos como salvoconducto ${ }^{43}$.

No debe haber sido fácil conseguir que quienes atraparon y condujeron indígenas a Chiloé para beneficiarse con su venta (la esclavitud de los indios de guerra era legal en el reino de Chile), los devolvieran gratuitamente. Los jesuitas y las autoridades de gobierno, que anteriormente se habían unido en expediciones de búsqueda de los Césares, ahora volvían a hacerlo debido a la presencia de informantes locuaces, en lenguas comprensibles, y que daban garantías. La Vida dice que el gobernador de Chiloé, D. Juan de la Barra ofreció toda ayuda para la restitución de los puelches, pero Gallardo dice, en cambio, que puso varios obstáculos que este último supo solucionar actuando de fiador ante el cabildo de Castro, comprometiéndose a pagar a los soldados que fueron a la maloca el precio de cada una de las "piezas" si es que en el futuro la Real Audiencia resolvía que la actuación había sido legítima. Además, facilitó su propia embarcación $e$ indígenas remeros para el viaje ${ }^{44}$. Más tarde, en mayo de 1670, ya habiendo emprendido Mascardi su viaje, Gallardo pidió al provincial de la Compañía de Jesús que enviase misioneros para atender a las "muy dilatadas provincias que están situadas a esotra banda de la cordillera de Chiloé, así de indios puelches como también de las dos ciudades de españoles y gente de Europa que llamamos Césares". Eran, para entonces, dos las ciudades.

solo se conoce en parte, por referencia, y gracias a Enrich, en la que expone su proyecto de misión en Patagonia: "Se dirá que me expongo a ser víctima de los bárbaros: ¡dichoso yo, si lograra derramar mi sangre por Cristo!" (Enrich, 1891, Tomo I, p. 739). Por entonces el colegio de Castro estaba compuesto, además del rector (Mascardi), por los padres José del Pozo (quien lo reemplazó en el cargo al ir a Nahuelhuapi), Bartolomé Camargo (llegado en 1666) y Esteban Carvajal (llegado en 1667) (Moreno, 2008, p. 128).

42 Furlong op. cit. (1945, p. 223).

43 Ese concepto, salvoconducto, usa Barcelos (2007, p. 231).

44 Carta de Francisco Gallardo al P. Rodríguez de León, Chacao, 20 de mayo de 1670. ARSI, Chile 5, f. 158-161. 
El virrey del Perú se enteró del proyecto de Mascardi a través de la carta que éste dirigió al procurador en Lima, P. Adamo, y se lo comunicó a la regente. Él no cuestionó su existencia. Al contrario, dio fe de ellos ante Mariana de Austria, porque, dice, "se reconoce hay esperanza de que se descubra la tierra que se llama de los Césares", náufragos, y le dice que dará "todo fomento a este descubrimiento, y ojalá se consiga en mi tiempo, que lo tendré a particular dicha de Dios"45. Los Césares de Argüello, por lo tanto, que habían "salido" de Chiloé a través del libro de Ovalle de 1646 , eran ahora un proyecto no solo a nivel virreinal, sino imperial.

\section{LOS TRES (Y NO CUATRO) VIAJES DE MASCARDI DESDE NAHUELHUAPI HACIA EL SUR}

Por la primera carta escrita a sus compañeros en Chiloé, en octubre de 1670, sabemos que había llegado a fines de febrero de ese año, siendo bien recibido de los puelches -los emisarios lo habían hecho posible- $y$ de unos caciques poyas del sur que se allegaron a Nahuelhuapi. El área del lago era un lugar de muy antigua ocupación (Lezcano et al. 2015), y de confluencia de grupos distintos (Boschín, 2002).

En esos caciques poyas -según Mascardi, más "bárbaros" que otros, ecuestres, adornados con chaquiras y objetos de metal de origen españolvio la oportunidad de acceder al meridión ${ }^{46}$. A los seis días de llegado, con la excusa de devolverles la visita, cruzó la laguna y avanzó a caballo. Vio entre ellos "pretales de cascabeles chicos y grandes de los antiguos de España", que dijeron haber conseguido de otros poyas "que viven el río abajo del desaguadero donde sale el sol". Volvió a la misión y en marzo o abril llegaron a ella otros caciques de más lejos, dice Mascardi, de cerca del Mar del Norte, que usaban "machetones o espadas anchas, frenos, pretales", y caballos adornados al uso de los españoles, que, averiguó, obtenían de

45 "Capítulo copia de una carta...". El virrey conde de Lemos a la reina, Lima, 26 de mayo de 1669. AGI, Audiencia de Lima, 68.

46 "Carta y relación que escribió el P. Nicolás Mascardi...", De los Poyas y octubre 15 de 1670, ARSI, Chile 5, f. 162$167 v$. "los españoles perdidos y poblados a la parte del sur que andamos buscando". Al darles a entender que los buscaba le respondieron, dice Mascardi, que sabían de las cartas que había enviado, pero que esos poyas no las dejaron pasar por no poner en riesgo su papel de proveedores de productos españoles a los poyas más lejanos. Se trata todo esto de las primeras imágenes europeas de un mundo ajeno, sin hitos ni referencias, con distancias, paisajes y grupos humanos advertidos por Mascardi a través de noticias fragmentarias que intentaba recomponer. Era, como se ha visto, una tierra indígena ya alterada por elementos materiales exógenos introducidos por naufragios y recaladas.

Le dijeron que volviese a escribir, lo que hizo en abril de 1670, que ellos intercederían, pero que no esperase respuesta antes de dos inviernos. Mientras tanto, ofrecían llevarle en el verano a un poya que de niño había vivido en la ciudad de españoles y hablaba su lengua. Además, pudo hablar con dos poyas que dijeron haber estado en ella. Así supo que tenía casas de tapia cubierta de pajas, trigo, cebada, vino, vacas, paños y lienzos, y que vivían en una isla que estaba en mar salado, a la que se llegaba después de navegar cuatro días. Dijeron que dos de los hombres que eran autoridad en la población se llamaban Aoballo y Gallecan ${ }^{47}$. Todo lo averiguado, concluye, es señal muy clara de que son los españoles que se perdieron con Argüello ${ }^{48}$.

Pasó el invierno en Nahuelhuapi, hubo viruelas, murió la reina. En los años sucesivos, aunque explica que pasa hambre y duerme en el suelo, se siente "en el paraíso terrenal" y es feliz. En primavera, el 15 de octubre fechó la primera carta que se conserva, pero ese verano de 1670-1671 no salió a buscar a los Césares, probablemente considerando el plazo de dos años de espera. En febrero de 1671 escribió al gobernador y al virrey del Perú dando cuenta de que poyas y puelches mostraban disposición a "recibir el yugo suave de la ley de cristo" (Enrich, 1891, p. 741), pero nada más se sabe de esas cartas, salvo la referencia de

47 Rosales, D. Conquista Espiritual..., AN, Fondo José Ignacio Víctor Eyzaguirre, Vol. 27, f. 169.

48 "Carta y relación que escribió el P. Nicolás Mascardi...", De los Poyas y octubre 15 de 1670, ARSI, Chile 5, f. 162$167 \mathrm{v}$. 
Enrich. Su objetivo es, como dice en una carta a su padre, ir a consolar tantas almas perdidas (Rosso, 1950, p. 311).

Escribió al P. Kircher para transmitirle sus observaciones sobre las mareas de los lugares visitados, y le contó de la ciudad de los Césares, anunciándole que existe "ad oram oceani orientalem... in quodam lacu ad $45^{\circ}$ ", y que les había mandado un mensaje ${ }^{49}$. En una segunda carta, también de febrero de 1671, le da más información: "me han llegado noticias muy favorables, es decir, que en el mar oriental, no lejos del Estrecho, se encuentra una colonia o población de gente europea. Bajo la altura del polo antártico a $47^{\circ}$ aproximadamente [la carta anterior dice $45^{\circ}$ ] $y$ de acuerdo a aquello que viene contado tienen su origen en España". Habían naufragado hacía 90 años [1580], se internaron en la tierra hasta resignarse a no seguir avanzando y poblarse "cerca de un lago" 50 . En Roma, por tanto, los Césares eran una realidad como la era Chiloé, y su existencia era tan verdadera como las mareas que describía al gran científico alemán.

A fines de ese año de 1671 debe haber sido el primer viaje largo ${ }^{51}$. En él vio quemazones hechas hacía dos años, indicios que interpreta como de "los españoles del sur", que habían estado buscando camino para comunicarse con los españoles de Valdivia o Chiloé, llegando hasta una laguna que estaba a 30 leguas de distancia de la de Nahuelhuapi ${ }^{52}$. Por la Conquista Espiritual se sabe que buscaba a otros Césares, unos españoles

49 Carta del P. Mascardi al P. Athanasius Kircher, Poyas ultra Andes Chiloenses, 10 de febrero de 1671. Archivo de la Pontificia Università Gregoriana, 565, Kircher, Misc. Epp. XI, f. 185-186.

50 Sigue: "Para informarme mejor de todo de esta miserable gente mandé de inmediato a uno de mis neófitos, despierto y conocedor de los caminos a buscar la verdad, informándome de sus costumbres, su modo de vivir, pero siendo el país por el cual debe viajar demasiado inculto $y$ carente de cualquier cosa necesaria para la sobrevivencia del hombre [...] imagino su retorno solo después de un tiempo...". Carta del P. Mascardi al P. Athanasius Kircher, En la región de los poyas más allá de los Andes de Chiloé, 1671. Archivo de la Pontificia Università Gregoriana, 566, Kircher, Misc. Epp. XII, f. 217-220v, publicada en parte y traducida del italiano al español por Acuña (2012).

51 La fecha viene dada por la carta al gobernador de Chile, Juan Henríquez, enviada desde Nahuelhuapi en octubre de 1672 , en que dice que ya le había informado del viaje situados en la costa del Pacífico, porque además de las noticias dadas por los indios que habían estado en la ciudad de españoles junto al Mar del Sur, las tuvo de otra "que está situada entre las cordilleras hacia la parte de los chonos y del mar austral". Le dijeron que los españoles de esa ciudad habían naufragado "hacia los chonos", en el mar austral, y que enterados de la presencia de un sacerdote en Nahuelhuapi, enviaron a dos en su busca. No pudiendo avanzar, despacharon a un indio "de sus vasallos" a que siguiera el camino hasta llegar al padre para pedirle que los fuese a ver. Para que les creyese, le enviaban una almilla de lana, un cuchillo labrado en la cacha y un pedazo de espejo ${ }^{53}$. Mascardi siguió avanzando hacia ellos, pero no pudo continuar por habérsele acabado bastimentos y agasajos, y dejó cartas para los españoles a un cacique que comunicaba con ellos. Al volver escribió al gobernador Henríquez (octubre de 1672) diciéndole que quedaba esperando la respuesta de los españoles ${ }^{54}$, y envió el cuchillo y la almilla a Santiago, como pruebas "de la ciudad nueva" 55.

Mascardi, en 1666, había navegado por el archipiélago de los Chonos, y pudo haber recibido de los "caucau" -como él los llama- noticias de foráneos, como otros antes y después de él las obtuvieron. Esta aproximación a la costa austral pacífica por noticias de los poyas podría haber estado reforzada por otras ya sabidas por Mascardi. La ocasión es muy similar a la de los puelches, porque conducidos a Chiloé como lenguas unos "caucau" capturados en las islas del sur, Mascardi

que hizo el año pasado "a los Chonos", carta que solo se conoce porque la reproduce la Conquista Espiritual.

52 Carta de Mascardi al gobernador de Chile, Juan Henríquez. Poyas, 8 de octubre de 1672, reproducida en Rosales, D. Conquista Espiritual..., AN, Fondo José Ignacio Víctor Eyzaguirre, Vol. 27, f. 171v-172v. También en Amunátegui, op. cit. (1881, Tomo III, pp. 97-99).

53 Rosales, D. Conquista Espiritual..., AN, Fondo José Ignacio Víctor Eyzaguirre, Vol. 27, f. 170.

54 Carta de Mascardi al gobernador de Chile, Juan Henríquez. Poyas, 8 de octubre de 1672, reproducida en Rosales, D. Conquista Espiritual..., AN, Fondo José Ignacio Víctor Eyzaguirre, Vol. 27, f. 171v-172v.

55 Pero en Santiago, reconocidos ambos objetos, se dedujo que se trataba de un navío del que no se sabía nada desde su zarpe hace trece años. Lo entregado por los indios eran restos de ese naufragio. Rosales, D. Conquista Espiritual..., reproducida en parte en AN, Fondo José Ignacio Víctor Eyzaguirre, Vol. 27, f. 171. 
aprendió su lengua e instruyó a fiscales, a quienes envió para que prepararan su llegada ${ }^{56}$. Estuvo varios meses entre ellos ${ }^{57}$.

En la carta a Henríquez de octubre de 1672 agrega, como novedad, que a comienzos del invierno había vuelto el mensajero sin haber cumplido su objetivo. Mascardi decidió ir él mismo ${ }^{58}$. "Salgo ahora", dice, "más aviado de comida y caballos", llevando lo recibido desde Chiloé para agasajos ${ }^{59}$. Sin embargo, no lo hizo. A los "originales", los Césares de Argüello, ya había sumado Mascardi a los náufragos establecidos en la "costa de los Chonos", y sabía también de otra ciudad en la costa del Mar del Norte. Por eso dice al gobernador de Chile, Juan Henríquez que Dios "tiene mucha gente perdida por acá, pues hay la de Argüello, la de Sarmiento, la de Íñigo López de Ayala y de otros navíos perdidos en estas costas" 60 .

Una carta de Mascardi al vice-provincial, conservada sin fecha, ha sido datada por Téllez como de fines de 1673 (Téllez, 1994; Gil,

56 "Io sto sin'ora in queste missioni e isole dell'Arcipelago di Chiloè, e questa primavera spero passare avanti verso la terra incognita dello stretto si Magagliano, a un'isola dove ho saputo che sono venuti molti barbari tutti nudi[...] Già ho battezzato alcuni di loro; hora sto studiando la loro legua per andaré a insegnare la fede, e battezzare gli altri, pero ritornerò a Chiloè questo medesimo anno" (Neri, 1950, p. 309).

57 Mascardi tenía un mapa del archipiélago de Chiloé y la costa hasta las islas Guaitecas. Lo sabemos porque fue copiado en un mapa hecho en 1699, que se titula: "Costa que corre desde la laguna de Quedar hasta la isla del Guafo y Guayteca sacada de la planta del padre Mascardi”. Está en "Derroteros de las costas del Pacífico desde California hasta el estrecho de Magallanes", título facticio de un manuscrito existente en la Biblioteca Nacional de España, fechado como c. 1699?, con 49 mapas, y aparece como autor Pedro Fernandes Queirós. Es el mapa N 47. http:// bdh-rd.bne.es/viewer.vm?id=0000001261

58 El mensajero volvió diciendo que los españoles se habían ido desde la tierra firme a su isla en la laguna, y que no pudo ir hacia ella por no haber barco. Por eso se vio obligado a dejar las cartas encargadas a uno de los caciques cercanos a la laguna. Pero después, el cacique más principal de los poyas del sur, que fue a verlo a Nahuelhuapi, le dijo "en secreto" a Mascardi que la dilación que ponían en darle "las buenas nuevas" era para que fuese el propio Mascardi a sus tierras. Ese cacique ofreció llevarlo consigo a las tierras del sur.

59 Carta de Mascardi al gobernador de Chile, Juan Henríquez. Poyas, 8 de octubre de 1672, en Rosales, D. Conquista Espiritual..., AN, Fondo José Ignacio Víctor Eyzaguirre,
1989, Vol. 2, p. 394, nota 995). Sin embargo, sostenemos que es de fines de $1672^{61}$. La carta es respuesta a una en la que el vice-provincial le manifiesta "escrúpulos" porque la misión no esté realmente asentada y que si él se va, se pierda lo hecho. Mascardi responde que no se puede abandonar, y le habla de la diversidad de ciudades de españoles, como a Henríquez. Aunque todas estas versiones de Césares son explicadas por Rosales en su Historia General, hasta ahora Mascardi solo había hablado de Argüello. Fruto de su estadía y las nuevas noticias acomodó su única ciudad a varias.

En abril de 1673 escribió a su hermano, diciéndole que pronto entrará a una ciudad "incógnita" de europeos perdidos hace cien años ${ }^{62}$. Pasó el invierno, y el 22 de septiembre de 1673 escribió al P. Carlo Francesco de Luca ${ }^{63}$. Del mes siguiente es una carta para agradecer al virrey conde de Lemos el envío de 200 ducados de plata, medallas de plata y 50 estampas de Nuestra Señora, y una "bella imagen de la virgen"64, que le envió el 4 de marzo de 1672.

Vol. 27, fjs. $171 v-172 v$.

60 Idem.

61 Esto, porque dice que "este año" recibió el sueldo de tres soldados, lo que, sabemos, ocurrió a comienzos de 1672 . Además, porque coincide en el contenido con la única que se ha conservado de las enviadas al gobernador Henríquez (Carta sin fecha de Mascardi a "mi padre vice-provincial", AN, Fondo Morla Vicuña, Vol. 20, pza. 18, f. 213v a 220, que es de donde la reproduce Téllez. Está también en Archivo General de Indias, Audiencia de Lima, 84), y porque, aunque dice "son tres años pasados en que no veo sacerdote", lo que ha hecho pensar que es de 1673, esos años son 1670,1671 y 1672 .

62 “... presto entrarò in una città incognita di europei persi per queste parti e mari di cento anni fa". Neri, "Un missionario..." op. cit., p. 588. Es la última carta que se tiene de él, dice Neri.

63 Carta de Mascardi al P. Carlo Francesco de Luca, Poyas, 22 de septiembre de 1673. ARSI, Chile, vol. 5, f. 168 y 168v. Reproduce en parte Rosso, "Nicolò Mascardi..." op. cit., p. 63: "Quatriennium iam ago apud Poyas regiones amplissimas atque hucusque inaccesos huius Australis Americae... Namque ab hac Nahuelguapensi regione ubi pedem fixi, scilicet in 40 fere gradu apud Andes, ad fretum usque Magellanicum Austrum versus, et ad oram usque maritimam Oceani orientalis, seu paraquariensis, omnes fere barbari... Austrum versus ad 200 pasuum milia iam penetravi... atque itineri paratus iterum ad cas regiones accedo ulterius ad 46 usque gradum penetraturus".

64 Solo se conoce esta carta porque la reprodujo: Buendía, 1693, libro, III, cap. IV: 245, que conocemos gracias a la referencia que da Enrich (1891, p. 741). 
Esto lo debe haber recibido en los primeros meses de 1673. Mascardi contestó agradeciendo con carta al vice-provincial en Lima, José María Adamo, por haber sido él quien lo remitió65. Dice Enrich que con esa fecha también escribió a sus superiores los resultados de su último viaje ${ }^{66}$.

En algún momento después del 12 de octubre de 1673 partió a su periplo final. Había pasado casi cuatro años aislado de otros españoles, comunicándose con Chiloé solo una vez al año. A pesar de eso, del hambre, frío y penurias, se siente dichoso cumpliendo el mandato de San Francisco Javier, que dos veces se le apareció para que fuese a misionar: una vez a los chonos y otra a los puelches y poyas. Reportó miles de bautizos, pero poco describió sus recorridos, solo mencionando la existencia de lagunas ${ }^{67}$.

Fue acompañado de algunos poyas, pero se fueron quedando en el camino dedicados a sus actividades habituales. Permanecieron con él cuatro indígenas de Chiloé y el cacique Manquehunay "con un hermano suyo", que le servían de guías. Siguiendo las noticias de indios sobre una población en el Mar del Norte, llegó a "un alojamiento capaz de seis cuadras de largo y ancho", en el que había pozos para sacar agua y muchas señales de haber habido allí gente de un navío extranjero (porque no había ninguna $\mathrm{cruz}^{68}$. Preguntando en la costa por la ciudad de los Césares no tuvo noticias de ella, por lo que se convenció que estaba "entre las cordilleras" (de los Andes) y se volvió hacia el occidente "hasta llegar a los poyas y guaitecas". Habían pasado cuatro meses y medio de viaje, en los que no paró de ir predicando ${ }^{69}$. El campamento visitado, dice el

65 La carta tiene fecha 12 de octubre de 1673, dice Enrich (1891, p. 744), citando a Buendía (1696, libro, III, cap. IV, p. 245).

66 Enrich (1891, p. 744) remite a Buendía (1693). Él, en p. 311, publica un extracto de la carta.

67 A pesar de lo impreciso que resultan sus recorridos $y$ distancias, Fonck, Furlong y otros han explicitado los supuestos lugares adonde llegó.

68 Rosales, D. Conquista Espiritual..., reproducida en AN, Fondo José Ignacio Víctor Eyzaguirre, Vol. 27, f. 174v.

69 Ibidem, f. 175. También Furlong (1945, p. 233).

70 Rosso (1950, p. 24), para dar esta fecha cita el Necrologio, ARSI, Chile, 6, f. 361v.

71 El gobernador de Chiloé, Chacao, 29 de octubre de 1674. Archivo General de Indias, Audiencia de Chile, 7.

72 Esto es, que yendo el padre con el cacique Manquehunay valdiviano Carvallo Goyeneche, quien escribe en 1796, era del John Narborough (Lo cita Enrich, 1891 , p. 743). Este comandante había salido en 1699 de orden del almirantazgo británico para reconocer el estrecho de Magallanes, recaló en varios puntos del Mar del Norte antes de cruzarlo, y llegó a Valdivia en diciembre de 1670.

Sin haber hallado nada, Mascardi emprendió el regreso a Nahuelhuapi, pero unos poyas que estaban en una gran fogata lo rechazaron, matando primero a Manquehunay y después al padre. Dieron muerte también a dos indígenas, pero "el hermano" de Manquehunay y otro alcanzaron a huir y llevaron la noticia a Nahuelhuapi. Por último, un indígena de Chiloé llamado Domingo, que le habían enviado los jesuitas para su compañía, quedó cautivo, salió en la noche y ocultó el cuerpo de Mascardi, enterrándolo con la cajita de ornamento que llevaba (Furlong, 1945, p. 234). Rosso dice que fue el 15 de febrero de $1674^{70}$.

La Vida, que es la que citamos, debió recoger lo que había trascendido en Chiloé: al menos existe una carta que lo informa, que es la del gobernador Gallardo al de Chile octubre de $1674^{71}$, en la que además de referir varios asuntos, comunica la muerte de Mascardi. Dice que a fines de marzo de 1674 había enviado a Nahuelhuapi mensajeros, que regresaron informando lo que ya hemos relatado ${ }^{72}$. El gobernador despachó gente de armas a averiguar las circunstancias de la muerte, el lugar de extranjeros y "las poblaciones que dicen [los indígenas] tiene el enemigo de Europa". Volvieron a Chiloé el 22 de octubre llevando Girón, el sargento mayor enviado, lo que halló en la casa de Mascardi ${ }^{73}$,

y cuatro indios, lo mataron "cerca del Estrecho" a los tres meses de haber salido. Antes de morir, dijo el informante, "había reconocido un cuartel en forma y alrededor de él muchos cadáveres de cuerpos muertos, y que dijo dicho padre que aquel cuartel era de moros por haberle reconocido sin ninguna cruz". El gobernador de Chiloé, Chacao, 29 de octubre de 1674. AGI, Audiencia de Chile, 7.

73 Algunos ornamentos, libros, una sotana, una custodia, muchas estampas, "y una hechura de Nuestra Señora de media vara de estatura, la cual está depositada en la iglesia de este fuerte, y se llevó a ella en procesión con la solemnidad que se pudo, hallándose presentes aquellos bárbaros me trajo el dicho Girón que la ayudaron a traer, que causó gran devoción y lágrimas en esta frontera". El gobernador de Chiloé, Chacao, 29 de octubre de 1674. AGI, Audiencia de Chile, 7. 
y entregó por escrito lo que averiguó "del que acompañó al dicho padre", documento que no tenemos, como tampoco una carta escrita a Gallardo por el hermano de Manquehunay, que se remitió al virrey.

Seis soldados enviados por el teniente Alonso de Córdoba y Figueroa, de orden del gobernador de Chile -Henríquez- fueron a Nahuelhuapi a recuperar el cuerpo y averiguar si estaban poblados los ingleses, por las noticias que se había tenido al respecto, dadas por un chono tomado en el archipiélago homónimo en 1674 y conducido a Chacao: Talcapillán. Los soldados condujeron a Concepción el cuerpo del padre, ornamentos y vasos sagrados, y fueron entregados al rector de la Compañía en dicha ciudad $^{74}$, donde fue sepultado ${ }^{75}$. Todo esto se supo pronto, y en Lima Adamo escribió que la muerte le vino "andando al discubrimento di due abitationi, ha fatto il nemico inglese in questo mare del Sud murate et artegliate; però il $\mathrm{P}$. Nicolò pensaba che erano di Spagnoli, et nel camino l'hanno occiso i medesimi indi" (Neri, 1950, p. 313).

La ciudad de los Césares, en realidad, las versiones de ella que fue conociendo Mascardi, fueron el motor de sus viajes. Ellos constituyen acciones concretas de la monarquía hispánica en un territorio lejano y completamente indígena, al parecer únicas en los siglos XVII y XVIII, y solo replicadas por las exploraciones de los jesuitas Cardiel y Falkner en la segunda mitad del XVIII, ambos salidos desde Buenos Aires. Por otro lado, la creencia sobre los Césares en Chiloé se mantuvo después de Mascardi. Jesuitas y no jesuitas preguntaron por ella a los indígenas en sus viajes misionales hacia el sur. Tan extendida estaba en el imaginario chilote que el piloto peninsular, José de Moraleda, quien estuvo varios años en Chiloé en las décadas de 1780 y 1790, vio la necesidad de hablar de los Césares y explicar por qué no era posible que existiera ${ }^{76}$.

74 Declaración del teniente Alonso de Córdoba y Figueroa, Santiago de Chile, 2 de junio de 1681. AN, Fondo Morla Vicuña, Vol. 20, f. 192v.

75 Así lo dice: Declaración del capitán Blas de Chavarría, Santiago de Chile, 3 de junio de 1681. AN, Fondo Morla Vicuña, Vol. 20, f. 195.

76 Moraleda, J., Diario de la navegación desde el puerto del Callao de Lima al de San Carlos de Chiloé y de éste al

\section{EPÍLOGO: MOROHUINCAS}

En 1681 los jesuitas solicitaron a las autoridades que enviasen 24 misioneros más, argumentando las muchas almas que quedaron bautizadas por Mascardi hasta el estrecho de Magallanes, pero abandonadas, aunque nada se mencionó sobre los españoles perdidos ${ }^{77}$. Se abrió camino y fundó una misión en Nahuelhuapi, pero su duración fue corta (1690-1717), luego de haber sido muertos sucesivamente varios de los misioneros (Urbina, 2008). Ninguno tuvo ocasión de avanzar hacia el Estrecho, aunque ese era el objetivo de la misión.

La llegada a Valdivia del comandante inglés Narborough en diciembre de 1670, generó la sospecha de que con él o tras de él llegasen otros barcos ingleses a repetir el daño causado por los holandeses en 1600 y 1643 en Chiloé y Valdivia. Una expedición dispuesta por el virrey para vigilar las costas desde Chiloé hasta el Estrecho condujo al regreso a la isla algunos canoeros, entre ellos al ya mencionado Talcapillán, quien dijo en 1674 que había dos formales colonias inglesas en las costas del sur, llamadas Callanac y Allauta (Urbina, 2015). Todo esto ocurrió cuando el gobernador de Chiloé era Francisco Gallardo, quien dio aviso al virrey de lo que decía Talcapillán, al mismo tiempo que le comunicaba la muerte de Mascardi y el campamento "de moros"78. Aunque se buscaron y no se hallaron, lo dicho por Talcapillán probablemente sea un eco de las recaladas de Narborough de ida y vuelta, o el recuerdo de otras anteriores. Por otro lado, cuatro ingleses de los que venían con Narborough, tomados prisioneros, declararon saber de la existencia de la ciudad de los "Sessares", indios ricos en oro, a la que se llegaba por un brazo de mar que penetraba a la tierra desde el estrecho de Magallanes (Urbina, 2017).

Las noticias de Césares, por lo tanto, eran frecuentes y renovadas, y su existencia era dada por verdadera no solo por españoles y por los

reconocimiento del archipiélago de los Chonos.... Archivo del Museo Naval de Madrid, fjs. 120v-129.

77 Carta del P. Francisco Ferreira pidiendo 24 misioneros para las provincias de Chile, Santiago de Chile, 8 de junio de 1681. AN, Fondo Morla Vicuña, Vol. 20, fjs. 202-204.

78 El gobernador de Chiloé, Chacao, 29 de octubre de 1674. AGI, Audiencia de Chile, 7. 
jesuitas que servían a esa corona, sino también por Inglaterra, al punto de enviar una expedición en su búsqueda un año antes que Mascardi saliera de Chiloé con el mismo objetivo.

\section{CONCLUSIONES}

Hasta ahora los estudios han hecho radicar en la personalidad de Mascardi uno de los capítulos más importantes en la trayectoria de la creencia en los Césares. Así ha sido porque cuando se ha tratado su figura ha sido siempre a través de los escritos del P. Rosales y asumiendo su mismo tono hagiográfico. Mascardi, sin embargo, provenía de un mundo jesuita en el que la ciudad existía. Leyó la obra del P. Ovalle, y convivió con el P. Rosales y con otros de sus correligionarios que habían buscado a los Césares y oído de indígenas lejanos comunicaciones sobre ellos. Además, para la Compañía de Jesús la obra misional debía extenderse a toda la tierra, y en Chiloé eso significaba penetrar a la inmensidad que tenían a sus espaldas, mucho más aún cuando un punto en ella era ya cristiano: descubrirlo permitiría darse la mano y vertebrar el territorio gentil intermedio. La relación entre la orden y los Césares no solo cubrió el siglo XVII en Chile y Tucumán, sino también el siglo XVIII, escribiendo sobre ellos o buscándolos otros jesuitas, cuestión que merece ser abordada en globalidad.

La creencia en los Césares era un sentir común por entonces que, como hemos dicho, trascendía las fronteras de Chiloé hasta alcanzar al virrey y a la corte española e inglesa. Francisco Gallardo, como otros gobernadores insulares, esperaba por fin dar con la ciudad: lo hizo enviando la expedición de Vera y respaldando la de Mascardi. Sus antecesores también habían dispuesto otras búsquedas, acciones que combinaban exploraciones geográficas y correrías misionales. La diferencia con respecto a las ocasiones anteriores no fue solo el haber llegado una llave a Chiloé -puelches, pero sobre todo, los poyas, que eran más australes y "nuevos" para Chiloé-, sino que algunos de ellos pudiesen darse a entender en "la lengua general", el mapuche-veliche. Ello permitió a los de Chiloé hacer hablar a la reina, y más aún después, cuando Mascardi aprendió la suya. Esta vez la expedición sería individual, terrestre y con apoyo concreto -se pensaba- de indígenas.
Las autoridades locales, virreinales y jesuitas estaban en consonancia en el actuar sobre territorios lejanos, sin contacto previo. La existencia allí de una colonia de españoles era algo indiscutible, y actuó como imán para la representación y significación del territorio y la ejecución de operaciones concretas en él, territorializándolo.

Este caso de los Césares se funda en la circulación de la información, que son noticias dadas por indígenas. Se trata de sus respuestas ante las preguntas de españoles sobre mundos a los que no podían acceder. No es posible saber qué y cómo se les preguntaba, pero es lógico pensar que los conocedores locales intentaban corresponder informando aquello que los foráneos querían confirmar, sobre todo porque su vida, posición o beneficio podía depender de ello.

Así como reafirman lo que los españoles quieren saber, también los conducen a lugares de foráneos como naufragios, sitios donde indígenas han depositado objetos de naufragios, puntos de recaladas. Ellos muestran los hitos externos a su paisaje, lo que va "marcando" el territorio y dotándolo de un contenido "occidental". Es el caso, por ejemplo, de una olla de bronce, entregada por indígenas a las autoridades de Chiloé, que llegó hasta Lima. O las ropas y objetos de metal que circulaban entre distintos grupos y que confirmaban la existencia de los Césares.

Iluminando este episodio en Chiloé, y sus precedentes inmediatos, es posible comprender mejor la idea de la ciudad de los Césares. Lejos de ser una leyenda, la idea de los Césares tomó cuerpo y adquirió diversas formas en una provincia que era el último lugar de la cristiandad occidental y, además, doblemente aislada por su condición de isla y de escindida del resto por existir en medio una tierra dominada por indígenas. En realidad, más que eso, Chiloé era una isla en medio de un enorme y desconocido territorio indígena que se extendía desde Concepción ( $37^{\circ}$ lat. S) hasta el cabo de Hornos (55 lat. S), donde estaba también la ciudad de los Césares. Si existía aquel enclave chilote en aquella inmensidad, podría existir otro. Parecía más fácil unir a ambas islas en el mar patagónico que unir a Chiloé con el resto de los territorios de la monarquía. Y eso es lo que se esperaba conseguir allegándose a los Césares. 


\section{AGRADECIMIENTOS}

Este artículo es fruto del proyecto Fondecyt Regular $\mathrm{N}^{\circ} 1180182$, "La creencia en la ciudad de los Césares en América colonial: 'noticias' de indígenas y circulación de la información, siglos XVI-XVIII". Agradezco a mi querido amigo Philippe Castejón, profesor de la Université de Lille, por las lecturas que hizo de este manuscrito, sus agudas observaciones sobre él, y por su sincero afecto. Asimismo, al profesor Jaime Valenzuela, de la Pontificia Universidad Católica de Chile, por compartir generosamente conmigo documentos que copió del Archivo de la Compañía de Jesús, en Roma.

\section{BIBLIOGRAFÍA}

Acuña, C. (Ed.) (2012). La curiosidad infinita de Athanasius Kircher. Una lectura a sus libros encontrados en la Biblioteca Nacional de Chile. Santiago de Chile: Ocho Libros Editores.

Acuña, C. (2012). El mundo subterráneo y la última carta de Nicolás Mascardi a su maestro Athanasius Kircher, en C.

Acuña, C. (2014). La expedición del padre Nicolás Mascardi a la Patagonia: una experiencia sobre las posibilidades y los límites del conocimiento en el siglo XVII. Revista de Historia Social y de las Mentalidades, 18(2), 33-57.

Amunátegui, M. L. (1881). La cuestión de límites entre Chile y la República Argentina. Santiago de Chile: Imprenta Nacional, Tomo III.

Angelis, P. de (1836). Colección de obras y documentos relativos a la historia antigua y moderna de las provincias del Río de la Plata. Buenos Aires: Imprenta del Estado, Tomo I.

Asúa, M. (2014). Science in the Vanished Arcadia. Knowledge of Nature in the Jesuits Missions of Paraguay and Río de la Plata. Leiden-Boston: Brill.

Barcelos, A. (2007). Entre a cordilheira e o mar: exploraçao e evangelizaçao jesuítica no Chile. História Unisinos, 11(2), 230-239.

Barcelos, A. (2013). O Mergulho no Seculum: exploraçao, conquista e organizaçao espacial jesuítica na América española colonial. Porto Alegre: Animal.

Barros Arana, D. (1999) [1884-1902]. Historia general del reino de Chile. Santiago de Chile: Editorial Universitaria y Centro de Investigaciones Diego Barros Arana, Tomo $\mathrm{V}$.
Bayo, C. (1913). Los césares de la Patagonia. Madrid: Imprenta de Juan Pueyo.

Biedma, J. (1987). Crónica histórica del lago Nahuel Huapí. Buenos Aires: Editorial Emecé.

Biehl, M. (2004). Nicolás Mascardi e a Carta-Relación de 1670: uma análise preliminar das observaçoes astronómicas realizadas pelo missionario jesuita. Oficina do Historiador, Suplemento Especial, Porto Alegre, 1780-1797.

Boschín, M. (2002). Indigenous History of Northwest Patagonia: Regional Identities during the Seventeenth and Eighteenth Centuries, en C. Briones y J. Lanata (Eds). Archaeological and Anthropological Perspectives on the Native Peoples of Pampa, Patagonia, and Tierra del Fuego to the Nineteenth Century (pp. 75-88). Westport: Connecticut, Bergin \& Garve.

Broggio, P. (2008). Niccolò Mascardi, en Dizionario Biografico degli Italiani, vol. 71. Roma: Istituto dell'Enciclopedia italiana.

Carvallo Goyeneche, V. (1865). Descripción históricojeográfica del reino de Chile (1796). Colección de Historiadores de Chile y de Documentos Relativos a la Historia Nacional, Tomo IX. Santiago de Chile: Imprenta La Estrella.

Deckmann, E. y Biehl, M. (2014). Sobre os céus e as marés do Pacífico: as observaçoes astronómicas do jesuita Nicolás Mascardi (Chile, século XVI). Revista Brasileira de História \& Ciências Sociais, 6(12), 104-124.

Enrich, F. (1891). Historia de la Compañía de Jesús en Chile. Barcelona: Imprenta de Francisco Rosal.

Estellé, P. y Couyoumdjian, R. (1968). La ciudad de los Césares: origen y evolución de una leyenda. Historia, 7, 283309.

Fonck, F. (1900). Viajes de Fray Francisco Menéndez a Nahuelhuapi. Valparaíso: Imprenta Guillet.

Furlong, G. (1943). Entre los tehuelches de la Patagonia. Buenos Aires: Talleres Gráficos San Pablo.

Furlong, G. (1945). Vida apostólica y glorioso martirio del venerable P. Nicolás Mascardi. Anales del Museo de la Patagonia, Francisco P. Moreno, 1.

Furlong, G. (1963). Nicolás Mascardi S.J. y su carta-relación (1670). Buenos Aires: Ediciones Theoria.

Gaune, R. (2017). Jesuitas de papel. Un balance historiográfico nacional a contraluz del global turn. Historia, 50(1), 305-329.

Gaune, R. y Rolle, C. (2015). ... Ruego a vuestra paternidad por las vísceras de Jesucristo. Retórica y vocación misionera de dos jesuitas italianos que deseaban las Indias (1640-1643). Revista de Humanidades, 32, 
261-275.

García, B. (1943-1946). El camino de Vuriloche. Revista Chilena de Historia y Geografía, 103, 104, 108 y 109.

Guarda, G. (2002). Los encomenderos de Chiloé. Santiago de Chile: Ediciones de la Universidad Católica de Chile.

Gil, J. (1989). Mitos y utopías del Descubrimiento. Madrid: Alianza, Vol. 2.

Hajduk, A., Albornoz, A., Lezcano, M., Montero, G., \& Fernández do Rio, S. (2013). De Chiloé al Nahuel Huapi. Nuevas evidencias materiales del accionar jesuítico en el gran lago (siglos XVII y XVIII). En M. Nicoletti y P. Núñez (Comp.), Araucanía-Norpatagonia: la territorialidad en debate. Perspectivas ambientales, culturales, sociales, políticas y económicas (pp. 243279). Bariloche: Universidad Nacional de Río Negro,

Hanisch, W. (1982). La isla de Chiloé, capitana de rutas australes. Santiago de Chile: Academia Superior de Ciencias Pedagógicas de Santiago.

Hanisch, W. (1985). El manuscrito de la Historia General de Chile del P. Diego de Rosales y su larga peregrinación. Jahrbuch für Geschichte Lateinamerikas, 22, 69-97.

Lasa, L. de y Luiz, M. (2011). Representaciones del espacio patagónico. Una interpretación de la cartografía jesuítica de los siglos XVII y XVIII. Cuadernos de Historia, 7-33.

Lezcano, M., Hajduk, A., \& Albornoz, A. (2015). Arqueología del lago Nahuel Huapi: modelos de uso de los ambientes y de los recursos faunísticos. Macroscopía, 4, 15-22.

Martín-Merás, M. (1986). Derrotero de la costa pacífica americana. JANO, 24-29 enero, XXX, 709, 2, Medicina y Humanidades.

Moreno, R. (2008). Misiones en Chile Austral: los jesuitas en Chiloé, 1608-1768. Sevilla: Escuela de Estudios Hispanoamericanos.

Neri, A. (1882). Un missionario al Chili nel secolo XVII. La Rassegna Nazionale, 9, 584-589.

Neri, A. (1886). Un missionario al Chili nel secolo XVII. Giornale linguistico di Archeologia, Storia e Letteratura, XIII, 306-315.

Nicoletti, M. (2004). Los jesuitas en el Nahuel Huapi: aproximaciones a una breve misión en la Patagonia (1669-1717). Memoria Americana, 12, 97-130.

Nicoletti, M. (2014). Pasado y presente: los jesuitas de la misión Nahuel Huapi (1670-1674 y 1704-1717) y la devoción Mariana. IHS. Antiguos jesuitas en Iberoamérica, 2(1), 41-64.

Olivares, M. (1874). Historia de la Compañía de Jesús en Chile (1593-1736). Colección de Historiadores de
Chile y documentos relativos a la historia nacional, Tomo VII, Introducción y Notas de Diego Barros Arana. Santiago de Chile: Imprenta Andrés Bello.

O’Neill, C. \& Domínguez, J. (Eds.). Diccionario histórico de la Compañía de Jesús. Roma: Universidad Pontificia Comillas, III, 2552-2553.

Page, C. (2013). El proyecto jesuítico para la explotación y ocupación de las costas patagónicas en el siglo XVIII. Temas Americanistas, 30, 23-49.

Porcel, M. (1958). Biografía del Nahuel-Huapí. Bariloche: Editorial Calfu-Lafquen.

Prieto, A. (2011). Missionary Scientist. Jesuit Science in Spanish South America, 1570-1810. Nashville: Vanderbolt University Press.

Revelli, P. (1926). Terre D'America e archivi d'Italia. Milano: Fratelli Treves Editori.

Rosso, G. (1950). Nicolò Mascardi missionario gesuita esploratore del Cile e della Patagonia (1624-1674). Archivum Historicum Societatis Iesu, 37-38, 3-74.

Storni, H. (1980). Catálogo de jesuitas de la provincia del Paraguay (cuenca del Plata) 1585-1768. Roma: Institutum Historicum.

Storni, H. (1992). Nicolò Mascardi sj 1624-1674, en Palocci, C. (a cura de). I Gesuiti. Fra impegno religioso e potere politico nella Republica di Genova, publicado en Quaderni Franzoniani, V, 2(10), 87-91.

Téllez, E. (1994). De tehuelches, Césares y australidades. Una relación postrera de Nicolás Mascardi S.J. (1673). Mapocho, 35, 265-276.

Terges, T. (1946). El padre Nicolás Mascardi, evangelizador de Araucanía. En Viaje, XIII, 150, 39-43.

Urbina, R. (2013) [1998]. Gobierno y sociedad en Chiloé Colonial. Valparaíso: Ediciones Universitarias de Valparaíso.

Urbina, X. (2008). La frustrada misión estratégica de Nahuelhuapi, un punto en la inmensidad de la Patagonia. Magallania,36(1), 5-30.

Urbina, X. (2015). El chono Cristóbal Talcapillán y su información sobre colonias inglesas en la Patagonia Insular, 1674. Boletín de la Academia de Historia Naval y Marítima de Chile, 19, 27-44.

Urbina, X. (2017). La expedición de John Narborough a Chile, 1670: la defensa de Valdivia, los rumores de indios, las informaciones de los prisioneros y la creencia en la Ciudad de los Césares. Magallania, 45(2), 11-36.

Urbina, X. (2019). Noticias locales e imperiales en el proceso de conformación de la creencia en la ciudad de los Césares (extremo sur de Chile, siglo XVII), en A. Martínez y M. Luque (Eds). América: problemas y posibilidades 
(pp. 197-216). Madrid: Asociación Española de Americanista y Universidad Complutense de Madrid,

Valenzuela, J. (en prensa). Cartas anuas y otros documentos de la Compañía de Jesús en Chile (siglo XVII). Santiago: Universidad Alberto Hurtado, Facultad de Filosofía y Humanidades/Pontificia Universidad Católica de Chile, Instituto de Historia (Colección "Biblioteca Jesuita de Chile").

Vignati, M. (1936). El asentamiento de la misión jesuita del lago Nahuel Huapi. Boletín de la Junta Histórica Numismática Americana, 8, 315-321.

\section{FUENTES}

Buendía, J. (1693). Vida admirable y prodigiosas virtudes del venerable y apostólico Padre Francisco del Castillo, de la Compañía de Jesús, natural de Lima... Madrid: Antonio Román.

Capítulo copia de una carta escrita por el padre Nicolás Mascardi de la Compañía de Jesús, rector del colegio de Chiloé, al padre Joseph María Adamo de la misma Compañía, procurador general de la provincia de Chile que asiste en esta corte de Lima, en 30 de enero de 1669. El virrey conde de Lemos a la reina, Lima, 26 de mayo de 1669, AGI, Audiencia de Lima, 68.

Carta del gobernador de Chiloé al gobernador de Chile, Chacao, 29 de octubre de 1674. AGI, Audiencia de Chile, 7.

Carta de Francisco Gallardo al P. Rodríguez de León, Chacao, 20 de mayo de 1670. ARSI, Chile 5, f. 158-161.

Carta del capitán Francisco de la Fuente de Villalobos, veedor general de la gente de guerra, Concepción, 20 de abril de 1651. AN, Fondo Morla Vicuña, Vol. 20, f. 30v.

Carta y relación que escribió el P. Nicolás Mascardi a los PP.

Bartolomé Camargo, rector de Chiloé, y Juan del Pozo y Esteban de Carvajal, de lo que sucedió en la entrada que hizo a los indios puelches y poyas siendo el dicho $\mathrm{P}$. rector de Chiloé, De los Poyas y octubre 15 de 1670. ARSI, Chile 5, f. 162-167v.

Carta del P. Mascardi al P. Athanasius Kircher, Poyas ultra Andes Chiloenses, 10 de febrero de 1671. Archivo de la Pontificia Università Gregoriana, 565, Kircher, Misc. Epp. XI, f. 185-186.

Carta del P. Mascardi al P. Athanasius Kircher, En la región de los poyas más allá de los Andes de Chiloé, 1671. Archivo de la Pontificia Università Gregoriana, 566, Kircher, Misc. Epp. XII, f. 217-220v.

Carta de Mascardi al gobernador de Chile, Juan Henríquez. Poyas, 8 de octubre de 1672, reproducida en Rosales, D. Conquista Espiritual..... AN, Fondo José Ignacio
Víctor Eyzaguirre, Vol. 27, f. 171v-172v.

Carta de Mascardi al P. Carlo Francesco de Luca, Poyas, 22 de septiembre de 1673. ARSI, Chile, vol. 5, f. 168 y $168 \mathrm{v}$.

Carta sin fecha de Mascardi a "mi padre vice-provincial", Archivo Nacional, Fondo Morla Vicuña, Vol. 20, pza. 18, f. $213 v$ a 220. También en Archivo General de Indias, Audiencia de Lima, 84.

Carta del gobernador de Chiloé, Chacao, 29 de octubre de 1674. AGI, Audiencia de Chile, 7.

Carta del P. Francisco Ferreira pidiendo 24 misioneros para las provincias de Chile, Santiago, 8 de junio de 1681. AN, Fondo Morla Vicuña, Vol. 20, fjs. 202-204.

Costa que corre desde la laguna de Quedar hasta la isla del Guafo y Guayteca sacada de la planta del padre Mascardi". Está en "Derroteros de las costas del Pacífico desde California hasta el estrecho de Magallanes, título facticio de un manuscrito existente en la Biblioteca Nacional de España, fechado como c. 1699?, Pedro Fernandes de Queirós, mapa $\mathrm{N}^{\circ}$ 47. http://bdh-rd.bne.es/viewer. vm?id=0000001261

Declaración que de orden del virrey del Perú D. Francisco de Borja, príncipe de Esquilache, hizo ante escribano Tomé Hernández, de lo sucedido en las dos poblaciones fundadas en el estrecho de Magallanes por P. Sarmiento de Gamboa (1620). En Sarmiento de Gamboa, P. (1768). Viaje al estrecho de Magallanes, en los años 1579 y 1580 y noticia de la expedición que después hizo para poblarle. Madrid: Imprenta Real de la Gazeta.

Declaración del teniente Alonso de Córdoba y Figueroa, Santiago, 2 de junio de 1681. AN, Fondo Morla Vicuña, Vol. 20, f. 192v.

Declaración del capitán Blas de Chavarría, Santiago, 3 de junio de 1681. AN, Fondo Morla Vicuña, Vol. 20, f. 195.

Descripción de las costas del Perú y Chile hasta cabo de Hornos y parte de la costa que va para Buenos Aires. Contiene multitud de vistas y planos. 1764, fechado en Lima, enero de 1764, sin firma. Archivo del Museo Naval de Madrid, Ms. 180 bis.

Letras anuas de esta provincia de Chile de los años 1629 y 30, Firmada por Gaspar Sobrino, en Santiago, 2 de abril de 1631. ARSI, Chile, Vol. 6, fjs. 63v-64v.

Letras annuas de la vice provincia de Chile a nuestro muy reverendo padre general Gostino Nikel, escritas por el padre Juan de Albiz, vice provincial de la vice provincia de Chile desde el año de 1657 hasta el de 1659. ARSI, Chile, Vol. 6, fjs. 282-282v.

Moraleda, J., "Diario de la navegación desde el puerto del 
Callao de Lima al de San Carlos de Chiloé y de éste al reconocimiento del archipiélago de los Chonos y costa occidental patagónica comprendida entre los 41 y 46 grados de latitud meridional, hecho de real orden y comisión del Exmo. Sr. Fr. Dn. Francisco Gil, virrey del Perú, por Dn. José de Moraleda y Montero alférez de fragata, primer piloto de la Real Armada en los años de 1792 a 1796. Tomo 2o". Archivo del Museo Naval de Madrid.

Ovalle, A. (2003) [1646]. Histórica Relación del Reino de Chile. Santiago: Editorial Pehuén.

Ramírez de Velazco, J. (1938). La Ciudad de los Césares. Averiguaciones practicadas en 1587 y 1589 por el gobernador de Tucumán, Ramírez de Velazco. Revista de la Biblioteca Nacional, 696-747.

Relación de Pedro de Oviedo, natural del condado de Nieva, y Antonio Cobos, carpintero de ribera, personas que venían en los dos navíos del obispo de Plasencia, y dicen lo siguiente..., sin fecha, (1567), en Medina, J. T. (1889). Colección de documentos inéditos para la Historia de Chile, Tomo III. Santiago: Imprenta Ercilla, Dcto. CVII, 465-468.

Rosales, Diego de, "Relación de lo singular del martirio del santo padre Nicolás Mascardi y de lo admirable de sus virtudes y milagros al N.R.P. General Paulo de Oliva”. ARSI, Chile 5, fjs. 178-179v.
Rosales, Diego de, Conquista Espiritual del reino de Chile. AN, Fondo José Ignacio Víctor Eyzaguirre, Vol. 27, pieza 14 , fjs. $161-175 \mathrm{v}$.

Rosales, D. (1877) [1674]. Historia General del Reino de Chile. Flandes Indiano. Valparaíso: Imprenta El Mercurio.

Tabula Geographica Regni Chile, de Alonso de Ovalle, 1646. Bibliothèque Nationale de France, département Cartes et plans.

Vázquez de Espinosa, A. (1948) [1629]. Compendio y descripción de las Indias Occidentales. Smithsonian Miscellaneous Collections, Vol. 108. Washington: Smithsonian Institution.

Vida apostólica y glorioso martirio del venerable P. Nicolás Mascardi de la Compañía de Jesús, Rector del Colegio de Castro, y misiones apostólicas de Chiloé, a quien envió el apóstol del Oriente S. Francisco Xavier a convertir a los gentiles poyas, guaitecas y otras naciones, y que muriese a sus manos por nuestra Santa Fe. ARSI, Fondo Gesuitico, Vol. 851.

Vida del Padre Juan López Ruiz, en Rosales, D. (1991). Seis misioneros en la frontera mapuche (Del Libro IV de la Conquista Espiritual del Reino de Chile, Volumen I, de Diego de Rosales). Introducción, Traducción y Notas de Valdés B., G. Temuco: Centro Ecuménico Diego de Medellín y Ediciones de la Universidad de la Frontera, pp. 223-233. 